\title{
PLAN HIDROLÓGICO NACIONAL Y PROGRAMA A.G.U.A.: REPERCUSIÓN EN LAS REGIONES DE MURCIA Y VALENCIA
}

\author{
Antonio M. Rico Amorós \\ Instituto Interuniversitario de Geografía \\ Universidad de Alicante ${ }^{1}$
}

\section{RESUMEN}

Tras el fracaso que supuso la tramitación del Anteproyecto de Plan Hidrológico Nacional (1993), la nueva iniciativa del Plan Hidrológico Nacional (2001) optó por un proceso de elaboración gradual, prolongado y con mayor rigor técnico. Se redujeron los trasvases y se prohibió la transformación en regadío con aguas trasvasadas en las cuencas receptoras. El Plan Hidrológico Nacional, aprobado por la Ley 10/2001, de 5 de julio, fue objeto de un intenso debate y participación pública. Esta tramitación contrasta con el expeditivo procedimiento seguido para la derogación del trasvase del Ebro a través del Programa A.G.U.A. mediante Real Decreto-Ley 2/2004, convertido luego en la Ley 11/2005. Todas estas cuestiones son objeto de análisis en este trabajo, con atención particular a las repercusiones que ha tenido en las regiones de Murcia y Valencia.

Palabras clave: Plan Hidrológico Nacional, trasvase del Ebro, desalación, usos del agua.

\section{ABSTRACT}

Following the failure of the preliminary drafting of the National Hydrologic Plan (1993), the new initiative established in the National Hydrologic Plan (2001) contemplates a more gradual, prolonged and technically rigorous process. Transfers were reduced and water that had been transferred was prohibited from being used for irrigation. The National Hydrologic Plan, approved by Law 10/2001, dated 5 July, was subject to intense discussion and public participation. The preliminary draft contrasts with the express procedure used to repeal the transfer of the Ebro through the A.G.U.A. Programme by Royal Decree-Law 2/2004, which later became Law 11/2005. All these issues are analysed in this study, with particular attention paid to repercussions in the regions of Murcia and Valencia.

Key words: National Hydrologic Plan, Ebro transfer, desalination, water uses.

1 Algunos resultados ofrecidos en este trabajo han sido elaborados en el marco del Proyecto de investigación «Modelos de desarrollo territorial y tipologías de consumo de agua potable en espacios turístico residenciales del litoral alicantino» (CSO2009-12772-C03-03) financiado por el Ministerio de Ciencia y Tecnología. 


\section{Introducción}

Fracasada la tramitación del Anteproyecto de 1993, la del Plan Hidrológico Nacional de 2001 intentó diferenciarse de la anterior en el procedimiento de elaboración y planteamiento general, incorporando las actuaciones previstas en los Planes Hidrológicos de cuenca y reduciendo sustancialmente los trasvases. En este proceso destacan una serie de hitos, recogidos en la Ley 10/2001, de 5 de julio, del Plan Hidrológico Nacional, como la aprobación de los Planes Hidrológicos de cuenca por Real Decreto 1664/1998, de 24 de julio, la publicación ese mismo año del Libro Blanco del Agua, la reforma de la Ley de Aguas de 2 de agosto de 1985 por la Ley 46/1999, de 13 de diciembre, y la promulgación de la Directiva 2000/60/ CE del Parlamento Europeo por la que se establece un marco comunitario de actuación en la política de aguas. Hitos destacados posteriores a la Ley 10/2001, de 5 de julio, del Plan Hidrológico Nacional, fueron: el Real Decreto Legislativo 1/2001, de 20 de julio, por el que se aprobó el texto refundido de la Ley de Aguas (T.R.L.A.), que incorporó la Directiva 2000/60/CE al ordenamiento jurídico español; la aprobación del Plan Nacional de Regadíos, por el Real Decreto 329/2002, de 5 de abril, que redujo significativamente las previsiones de transformación de nuevos regadíos; asimismo, debe destacarse la expeditiva paralización de las obras del trasvase del Ebro, iniciadas en febrero de 2004, por el Real Decreto Ley 2/2004, y su sustitución por el llamado programa A.G.U.A.; éste último fue revisado al año siguiente por la Ley 11/2005, de 22 de junio, que modificaba la Ley 10/2001, del Plan Hidrológico Nacional; y finalmente, cabe resaltar el Real Decreto 907/2007, de 6 de julio, por que se aprobó el Reglamento de la Planificación Hidrológica, que desarrolla aspectos normativos previstos en el texto refundido de la Ley de Aguas y en la propia Directiva 2000/60/CE. La transposición de esta Directiva abrió, a partir de 2003, una nueva etapa de planificación hidrológica que tendría que haber concluido en 2009, con la aprobación de los nuevos Planes Hidrológicos de cuenca en cada demarcación hidrográfica (Art. 13).

\section{El Plan Hidrológico Nacional: tramitación, objetivos y contenidos}

La Ley 29/1985, de 2 de agosto, otorgó al Plan Hidrológico Nacional la consideración de norma de planificación con mayor rango dentro del ordenamiento jurídico en materia de aguas. Los objetivos generales de la planificación hidrológica se encaminaban a lograr «el buen estado ecológico del dominio público hidráulico y la satisfacción de las demandas de agua, el equilibrio y armonización del desarrollo regional y sectorial, incrementando las disponibilidades del recurso, protegiendo su calidad, economizando su empleo y racionalizando sus usos en armonía con el medio ambiente y los demás recursos naturales» (Art. 40.1 T.R.L.A.). La formulación, elaboración y tramitación del Plan Hidrológico Nacional, hasta adquirir rango de ley, siguió un proceso reglado establecido en la propia Ley de Aguas, incluida una fase de participación pública. Objetivo esencial del mismo era dar respuesta a cuestiones y a problemas planteados en los planes hidrológicos de cuenca que sólo podían abordarse desde una perspectiva integrada y nacional. Por ello, una etapa fundamental previa a la elaboración del Plan Hidrológico Nacional fue la aprobación de los planes hidrológicos Norte I, Norte II, Norte III, Duero, Tajo, Guadiana I, Guadiana II, Guadalquivir, Sur, Segura, Júcar, Ebro y cuencas intracomunitarias de Cataluña, mediante el Real Decreto 1664/1998, de 24 de julio. Posteriormente, el Plan Hidrológico de las Islas Baleares fue aprobado por el Real Decreto 378/2001, de 6 de abril, y el Plan Hidrológico de Galicia-Costa, por el Real Decreto 103/2003, de 24 de enero. Los principales contenidos del Plan Hidrológico Nacional, particularmente los relativos a trasvases de agua, estaban determinados en la Ley de Aguas (45.1. T.R.L.A.), que señala que «se aprobará por Ley y 
contendrá, en todo caso: a) Las medidas necesarias para la coordinación de los diferentes planes hidrológicos de cuenca; b) La solución para las posibles alternativas que aquéllos ofrezcan; c) La previsión y las condiciones de las transferencias de recursos hidráulicos entre ámbitos territoriales de distintos planes hidrológicos de cuenca; d) Las modificaciones que se prevean en la planificación del uso del recurso y que afecten a aprovechamientos existentes para abastecimiento a poblaciones o regadíos».

Asimismo, es de destacar el largo y activo proceso de participación pública que precedió a la publicación de la Ley 10/2001, de 5 de julio, del Plan Hidrológico Nacional, con la discusión y aprobación de los planes de cuenca, la publicación del Libro Blanco del Agua, en 1998; la tramitación de los grandes ejes de la planificación hidrológica en el seno del Consejo Nacional del Agua, con el informe favorable al Plan Hidrológico Nacional de 30 de enero de 2001, la participación e información publica de los documentos técnicos que sirvieron de base a la redacción del Plan Hidrológico Nacional, el trámite parlamentario que antecedió a la aprobación del Plan Hidrológico Nacional, el proceso de participación pública que acompañó a la evaluación ambiental estratégica del Plan Hidrológico Nacional, en 2002, y la declaración de impacto ambiental sobre el proyecto de transferencias autorizadas por el art. 13 de la Ley del Plan Hidrológico Nacional, de 2003. La aprobación del Plan Hidrológico Nacional cumplió todos los trámites de participación pública establecidos en la Ley de Aguas, destacando el informe preceptivo del Consejo Nacional del Agua al que obligaba el Art. 20.1 a del Texto Refundido de la Ley de Aguas (T.R.L.A.) «antes de su aprobación por el Gobierno para su remisión a las Cortes». Desde 25 de septiembre de 2000 a 22 de enero de 2001 se celebraron 13 sesiones de trabajo de la Comisión Permanente del Consejo Nacional del Agua, para debatir los contenidos de la documentación técnica. Tras esta etapa de debate, el informe final fue sometido a votación en el pleno del Consejo Nacional del Agua, el 30 de enero de 2001, con 69 votos a favor, 15 en contra y 1 abstención. Debe resaltarse que votaron favor los vocales de las comunidades autónomas gobernadas por el Partido Popular, más el País Vasco, presidida por el Partido Nacionalista Vasco. También fue positivo el voto de las regiones de Extremadura y Castilla-La Mancha, gobernadas por el Partido Socialista, que vieron satisfechas sus demandas de inversiones económicas y mayores dotaciones de Júcar, Tajo y Guadiana para la expansión de regadíos. En cambio, hay que hacer notar el voto contrario al Plan Hidrológico Nacional que emitieron cuatro de los vocales de la comunidad científica propuestos por el Ministerio de Ciencia y Tecnología y por el Ministerio de Medio Ambiente, que se sumaron a los realizados por los colectivos ecologistas, algunas organizaciones agrarias (COAG y UPA) y representantes de las regiones de Aragón, Asturias, Andalucía y Baleares (MMA, 2002).

\subsection{Estructura y contenidos de la documentación técnica sometida a información pública}

El 5 de septiembre de 2000, se presentó el borrador de Anteproyecto de Ley del Plan Hidrológico Nacional al Consejo Nacional del Agua, órgano consultivo que debía informar preceptivamente dicho plan, antes de su remisión a las Cortes. En dicho Consejo, integrado por 91 miembros, se encontraban representadas las comunidades autónomas, Administración del Estado, ayuntamientos, organismos de cuenca, organizaciones profesionales, colectivos ecologistas, usuarios del agua y representantes de las universidades. El proceso de participación pública se completó con la remisión del Anteproyecto a técnicos y expertos universitarios en materia de aguas para su valoración e informe, y se abrió también una fase de alegaciones, comentarios y sugerencias al Plan por parte de cualquier interesado. La documentación sometida a información y participación pública se componía de los seis documentos siguientes: 
1) El Anteproyecto de Ley del Plan Hidrológico Nacional, en su versión de borrador, tenía 31 artículos, distribuidos en dos títulos y cuatro capítulos, más dos disposiciones transitorias, dos disposiciones derogatorias y una disposición final. También incorporaba un extenso Anexo II, de 25 páginas, que recogía el listado de inversiones y la relación de actuaciones previstas por cuencas hidrográficas durante el período 2000-2008.

2) El volumen 1 dedicaba alrededor de 130 páginas a la «Delimitación y asignación de recursos en acuíferos compartidos» en dos o más ámbitos territoriales de organismos de cuenca. Para las regiones de Murcia y Valencia, reviste gran interés el análisis de entradas, salidas y usos del agua que se ofrece de las unidades hidrogeológicas de Jumilla-Villena, Serral-Salinas, Quibas y Sierra de Crevillente, que padecen una grave situación de sobreexplotación (MMA, 2000 a).

3) El volumen 2 se dedicó al «Análisis de antecedentes y transferencias planteadas», con dos capítulos claramente diferenciados. El primero de ellos analizaba los antecedentes históricos de los trasvases de agua realizados en España desde época romana al Anteproyecto de Ley de Plan Hidrológico Nacional de 1993, con referencias directas a los siguientes hitos: I Plan General de Canales de Riego y Pantanos o Plan Gasset, de 1902; el Plan Nacional de Obras Hidráulicas de 1933, dirigido por D. Manuel Lorenzo Pardo; el Plan de Ampliación y Mejora de los Riegos de Levante, propuesto por Félix de los Ríos Martín, en 1937; el Plan Nacional de Obras Públicas de 1940; las previsiones de transferencias recogidas en los Planes de Desarrollo Económico y Social; el Anteproyecto General de Aprovechamiento de los Recursos Hidráulicos del Centro y Sureste de España, complejo Tajo-Segura, de 1967; y el Sistema Integrado de Equilibrio Hidráulico Nacional (SIEHNA), que constituía la pieza esencial del Anteproyecto de Ley del Plan Hidrológico Nacional, de 1993. El segundo capítulo de este volumen dedicaba más de un centenar de páginas a la «Descripción y análisis de las transferencias planteadas», si bien se advertía que el planteamiento de las distintas opciones de trasvases parte sobre todo de los trabajos realizados por la Dirección General de Obras Hidráulicas y Calidad de las Aguas con motivo del Anteproyecto de Plan Hidrológico Nacional de 1993. Entre las alternativas valoradas para resolver el déficit estructural de las cuencas del Júcar, Segura y Sur se incluían los trasvases siguientes: a) La transferencia Ebro-Júcar-Segura, con posibles puntos de toma aguas abajo del embalse de Flix, azud de Cherta o Amposta; b) Las transferencias Duero-Tajo (ATS), con tres posibles tomas a partir del Alto Duero, afluentes del Duero por su margen derecha y Bajo Duero, con diferentes trazados, que tendrían como destino la presa de Bolarque, en la cabecera del acueducto Tajo-Segura (ATS); c) Las transferencias Tajo-ATS respondían a un finalidad bastante similar a la anterior, aunque en este caso para alcanzar la máxima capacidad de transporte prevista para el trasvase Tajo-Segura los caudales serían aportados por el propio Tajo o por afluentes de su margen derecha (Jarama, Tiétar y Alberche); d) La transferencia Ebro-Cuencas Internas de Cataluña consideraba dos posibles alternativas, con trazados y puntos de toma muy diferentes. La primera opción era la realización de un trasvase desde el Bajo Ebro al Llobregat, y la segunda desde el Noguera Pallaresa al Llobregat; e) La transferencia Ródano-Barcelona.

4) El volumen 3, de 390 páginas, desarrollaba un «Análisis de los sistemas hidráulicos» afectados por los posibles trasvases planteados en el Anteproyecto de Plan Hidrológico Nacional. El diagnóstico de este capítulo parte, en gran medida, de los resultados que recogía el Libro Blanco del Agua (1998), pero se ofrece un análisis de mayor detalle en aspectos cruciales como la viabilidad hidrológica de las transferencias, con caudales máximos trasvasables considerando la hipótesis del cambio climático y, tras atender demandas futuras en las cuencas cedentes, la estimación estricta de las necesidades reales de agua en las zonas receptoras y las condiciones técnicas de los trasvases planteados. 
Para las regiones de Murcia y Valencia, cobraba gran interés el diagnóstico que se acompaña de las cuencas del Segura-Almería y Júcar, que incluye: análisis de recursos superficiales e hipogeos, con especial referencia a la sobreexplotación de acuíferos; valoración de las demandas de abastecimiento, regadío y ambientales; y, además, análisis de los elementos e infraestructuras de regulación superficial y transporte de las posibilidades de ahorro en regadíos y abastecimientos, y efectos del posible cambio climático. En el caso concreto de la cuenca del Segura-Almería, que se trató como un sistema conjunto, el análisis reveló que, sin nuevas transferencias externas y sin las correspondientes infraestructuras de regulación y transporte, la mayoría de unidades de demanda presentarían fallos de suministro de forma permanente. Incluso aunque se aportaran recursos externos, la insuficiente capacidad de las infraestructuras hidráulicas actuales provocaría fallos de suministro en 6 unidades de demanda, en especial destacando los regadíos del Guadalentín, Mazarrón, Águilas y Almería, que obligan a dimensionar el Canal de la Margen Derecha del Postrasvase Tajo-Segura. Para atajar la sobreexplotación de acuíferos y satisfacer las demandas existentes, y con la premisa de no ampliar regadíos, se precisaría que el acueducto Tajo-Segura y otros posibles trasvases, bien del propio Tajo o de otras cuencas, aportasen en torno a $1.100 \mathrm{hm}^{3} / \mathrm{año}$; de los cuales, unos $650 \mathrm{hm}^{3} /$ año deben garantizarse a través del acueducto Tajo Segura (ATS), para satisfacer todas las unidades de demanda.

El análisis de la cuenca del Júcar arrojaba como principal resultado una situación global de escasez coyuntural de agua, con un sistema de explotación - Júcar - que registra suficiencia frente a otros que padecen fuerte déficit estructural, sobre todo en Alicante. Para poner fin a estos problemas se proponen aportes externos, que se incorporarían al sistema desde el Ebro o desde el ATS. En todo caso, para eliminar los fallos de suministro en todas las unidades de demanda, se precisaría una transferencia mínima estructural del bajo Ebro de unos $150 \mathrm{hm}^{3} /$ año, ya que los aportes externos procedentes exclusivamente del Tajo o del Duero no resolverían el problema por muy elevada que fuese su cuantía. Así, para el ámbito del Júcar se plantea que «las soluciones más equilibradas consisten en una suma de aportes externos de unos $250 \mathrm{hm}^{3} /$ año, con un mínimo procedente del Ebro de $150 \mathrm{hm}^{3} /$ año, es decir, unos $150 \mathrm{hm}^{3} /$ año del Ebro y 100 del ATS, o $200 \mathrm{hm}^{3} /$ año del Ebro y 50 del ATS» (MMA, 2000 c).

5) Con una estructura de 5 capítulos y 266 páginas, el volumen 4 se dedicó a los «Análisis ambientales»; y se inicia con una apretada síntesis de las leyes, normas y directivas ambientales que deberían cumplir las principales actuaciones del Plan Hidrológico Nacional. En el capítulo de afecciones en origen, se ofreció un breve descripción de las repercusiones ecológicas más significativas de las distintas transferencias. En este caso, se diferenciaron, por un lado, las propuestas de Tajo y Duero, a las cuales se prestó mínima atención por tratarse de ríos internacionales con condiciones hidrológicas regidas por acuerdos internacionales (Albufeira); y, por otra parte, las relativas a la formación deltaica del Ebro. En este caso, se resaltaron las mayores amenazas que penden sobre el delta, principalmente la fuerte reducción del transporte de sedimentos desde la construcción en el Bajo Ebro de los embalses de Mequinenza $\left(1.530 \mathrm{hm}^{3}\right)$, en 1964, y Ribarroja (206 hm³ $)$, en 1969; y, por otro lado, el problema de la intrusión de agua marina, mediante una cuña, que, en condiciones naturales y en años secos podría avanzar hasta las cercanías de Tortosa. En el apartado de afecciones en las cuencas receptoras, se valoraron principalmente los efectos que provocaría la mezcla de aguas con diferente calidad, la trasferencia de especies biológicas y las repercusiones socioeconómicas de los trasvases planteados. En el caso concreto de la opción del Duero, la toma planteada en San Esteban de Gormaz (Soria) proporcionaba agua de extraordinaria calidad y apta para todo tipo de uso, mientras que la opción de trasvase desde el embalse de Villalcampo (Zamora) aportaba agua de peor calidad, además 
del inconveniente añadido que suponía un trazado de mayor recorrido. De las alternativas de trasvase del Tajo, la única que resultaba viable en términos de calidad del agua era la del Tiétar, mientras que otras opciones como las del Jarama, Toledo o Azután tropezaban con grandes dificultades por los elevados contenidos en fosfatos, amonio, sulfatos y $\mathrm{DBO}_{5}$ que propician los vertidos de residuales del área metropolitana de Madrid. Las analíticas del Bajo Ebro, confirmaban que la conductividad es uno de los principales parámetros que amenazaba el cumplimiento de la normativa de aguas prepotables, ya que los valores medios se sitúan en la mayoría de estaciones en torno a los $1.000 \mu \mathrm{S} / \mathrm{cm}$, que es el límite establecido en la misma, con máximos de $1.200 \mu \mathrm{S} / \mathrm{cm}$ a finales de verano y mínimos por bajo de $900 \mu \mathrm{S} / \mathrm{cm}$ en mayo y junio.

6) El último tomo de documentación técnica se consagró a los «Análisis Económicos», con 325 páginas y 5 capítulos dedicados a valorar la optimización económica de los trasvases a partir de un balance de los costes y beneficios de las distintas alternativas propuestas. En el apartado de costes, se estimaban las inversiones requeridas para la construcción y, se comparaban los resultados obtenidos con los precios del agua vigentes en las cuencas receptoras, distinguiendo su procedencia, los tipos de demanda y su capacidad de pago en relación con los costes finales del agua trasvasada. Los cálculos económicos de las transferencias incorporaron los llamados «costes de compensación» a las cuencas cedentes, que ya se aplican con el Tajo-Segura, asignándoles un valor inicial de $0,03 \square / \mathrm{m}^{3}$. Los resultados obtenidos en el análisis de las distintas trasferencias señalaban que la mejor opción era la solución litoral, desde el Bajo Ebro a las Cuencas Internas de Cataluña Barcelona y hacía las del Júcar, Segura y Sur, con un coste medio de $0,31 \square / \mathrm{m}^{3}$ frente a los 0,39 y $0,41 \square / \mathrm{m}^{3}$ de las soluciones intermedia e interior, respectivamente.

El Consejo Nacional del Agua estimó que las determinaciones del Plan Hidrológico Nacional eran correctas, aunque solicitó la incorporación de una serie de recomendaciones, que mejoraron sustancialmente la redacción del Anteproyecto de Ley. Las modificaciones afectaron a la propia exposición de motivos de la Ley 10/2001, de 5 de julio, del Plan Hidrológico Nacional, que incorporó los principios de la Directiva Marco del Agua 2000/60/ $\mathrm{CE}$, sobre todo los relativos a recuperación de costes, participación social y buen estado ecológico de las masas de agua. Estos objetivos también se plasmaron en el articulado definitivo de la Ley del Plan Hidrológico Nacional, así el Capítulo I, dedicado a las «Medidas de coordinación de los Planes Hidrológicos de cuenca», incluyó la modificación de los artículos 5, 6, 7 y 9 para incorporar «los principios de generales de precaución, racionalidad, sostenibilidad, protección del dominio público hidráulico, buen estado ecológico de las aguas y la protección de los caudales ambientales». En el Capítulo III, que desarro1la la «Previsión y condiciones de las transferencias», se establecieron unos «Principios generales» (Art. 12) que obligan a garantizar «las demandas actuales y futuras de todos los usos y aprovechamientos de la cuenca cedente, incluidas las restricciones medioambientales, sin que pueda verse limitado el desarrollo de dicha cuenca amparándose en la previsión de transferencias». Las recomendaciones del Consejo Nacional del Agua elevaron significativamente las condiciones exigidas a las transferencias autorizadas en la Ley, que obligaban a someter a una «evaluación de impacto ambiental de manera conjunta todos los proyectos relativos a las mismas» (Art. 15). Además, para las transferencias de $1.050 \mathrm{hm}^{3} /$ año con origen en el Bajo Ebro, que se autorizaban en el artículo 13 de la Ley, se imponían una serie de restricciones, que garantizaban los caudales ecológicos en el Delta del Ebro y el funcionamiento de los sistemas hidráulicos de la cuenca, sin generar ningún tipo de servidumbre hacia los trasvases previstos (Art. 16). También se impusieron limitaciones adicionales en el uso del agua trasvasada (Art. 17), restringiendo su aprovechamiento a abastecimientos en alta existentes, regadíos deficitarios con derechos de uso acreditados 
y áreas de uso dependientes de acuíferos sobreexplotados. Igualmente, se propuso la modificación del artículo 22, sobre «Régimen económico financiero del trasvase», para actualizar cada año la cuota ambiental del «canon del trasvase». Por otro lado, se introdujo la obligación de elaborar planes especiales de gestión de sequías para cada demarcación hidrográfica y planes de emergencia ante situaciones de sequía para los abastecimientos urbanos que atienden más de 20.000 habitantes (Art. 27). El Consejo Nacional del Agua también solicitó la incorporación de otros artículos específicos de fomento del uso racional de las aguas para abastecimiento (Art. 30) y otras medidas de sensibilización, educación e investigación en materia de recursos hídricos (Art. 34). Tras la fase de información pública, el 9 de febrero de 2001 el Consejo de Ministros aprobó el Anteproyecto de Ley de Plan Hidrológico Nacional, y el texto fue remitido a las Cortes para su tramitación parlamentaria. El Pleno del Congreso de los Diputados aprobó el Proyecto de Ley, el 30 de abril de 2001, tras la incorporación de 56 enmiendas propuestas por diferentes grupos parlamentarios, que mejoraron los contenidos de la Exposición de Motivos, las determinaciones de 13 artículos de la Ley y de 3 Disposiciones Adicionales, destacando la décima, que establecía la elaboración de un Plan Integral del Delta del Ebro. Finalmente, el Pleno del Senado aprobó el Proyecto de Ley el 20 de junio de 2001 y, tras la sanción y promulgación real, se publicó en el Boletín Oficial del Estado el viernes 6 de julio, como Ley 10/2001, de 5 de julio, del Plan Hidrológico Nacional.

\subsection{Documentos e informes técnicos posteriores a la Ley 10/2001, de 5 de julio, del Plan Hidrológico Nacional: la Evaluación Ambiental Estratégica (2002)}

Al año siguiente de la tramitación y aprobación de la Ley 10/2001, el Ministerio de Medio Ambiente elaboró la Evaluación Ambiental Estratégica del Plan Hidrológico Nacional, con una metodología y estructura de contenidos desarrollada conforme a lo establecido en la Directiva 2001/42/CE, relativa a la evaluación de los efectos de determinados planes y programas en el medio ambiente. El documento técnico, que se compone de 186 páginas y se estructura en 10 capítulos, se remitió a la Dirección General de Medio Ambiente de la Comisión Europea en enero de 2002. Tras su análisis, la responsable de dicha Dirección General, Catherine Day remitió una detallada valoración del mismo al Ministerio de Medio Ambiente, haciendo notar que «el documento presenta una información exhaustiva sobre la problemática del agua en España, y la transferencia de agua prevista desde el Ebro, así como sus efectos en el Delta del Ebro y en los sistemas receptores». En el mismo escrito se solicitaban informaciones adicionales sobre cuestiones relativas a situación actual y evolución de consumos, cambio climático, precios del agua y protección del Delta del Ebro y también se recordaba «la obligación de llevar a cabo una Evaluación de Impacto Ambiental para cualquier proyecto de trasvase de recursos superior a $100 \mathrm{hm}^{3}$, de acuerdo con lo dispuesto en la Directiva 85/337/CEE».

La Evaluación Ambiental Estratégica permitió completar y ampliar significativamente la información ofrecida en la documentación técnica del Anteproyecto de Plan Hidrológico Nacional, especialmente en la selección de las alternativas con menor coste ambiental y económico para resolver los problemas de escasez de agua en España, que afectan a los ámbitos de planificación del Segura, Sur (Almería), Júcar y Cuencas Internas de Cataluña. Las distintas alternativas se agruparon en cuatro «opciones estratégicas», que incluían las siguientes propuestas: a) En la «Opción 0. No actuación» no se planteaba ninguna intervención pública para resolver los problemas de insuficiencia de agua en las cuencas deficitarias; b) La «Opción 1. Reducción programada de la demanda» preveía el mantenimiento de las aportaciones del trasvase Tajo-Segura, el incremento de la reutilización de 
residuales y una reducción de los consumos agrícolas con el abandono de superficies de regadío para equilibrar la oferta y las demandas de agua; c) En la «Opción 2: Desalación a gran escala» se proponía satisfacer todo el déficit de agua en las cuencas deficitarias mediante la desalación de agua marina y la reutilización de residuales, manteniendo los consumos en valores similares a los actuales; d) La «Opción 3: Transferencias entre cuencas» incluía la realización de trasvases, la desalación para el abastecimiento a poblaciones costeras, iniciativas para el ahorro de agua y la prohibición de nuevos regadíos en las zonas receptoras de las transferencias. Tras la formulación de estas opciones, se llevó a cabo un estudio comparado de todas ellas atendiendo a criterios como el ámbito de planificación afectado, impacto sobre los recursos y los ecosistemas, escenarios futuros de demandas y consumos, racionalidad económica y repercusiones socioeconómicas.

Como resultado de este análisis de viabilidad, se descartaron las Opciones 0 y 1 por la elevada incertidumbre que provocaban en la satisfacción de las demandas de agua, por no aportar una solución definitiva a los problemas de sobreexplotación de acuíferos y por sus efectos negativos sobre usos del agua de gran trascendencia social y económica. La «Opción 2: Desalación a gran escala» no se descartaba completamente, ya que cumplía con algunos de los criterios establecidos. Sin embargo, la desalación masiva de agua marina conllevaría costes económicos y efectos ambientales muy elevados, asociados principalmente al consumo energético y a los vertidos de salmuera, lo que motiva que «sin grandes subvenciones económicas esta opción no puede cubrir satisfactoriamente, por sí sola, los problemas de escasez en las áreas deficitarias» (MMA, 2002). Finalmente, la «Opción 3: Transferencias entre cuencas» fue la mejor valorada para solucionar los problemas de escasez de agua en las Cuencas Internas de Cataluña, Júcar, Segura y Sur en el marco del Plan Hidrológico Nacional. Esta opción fue considerada la más robusta, al aportar una mayor garantía y diversificación de las fuentes de suministro, con empleo de los recursos renovables y la reutilización de residuales, más las aguas trasvasadas, que serían completadas puntualmente con desalación en zonas costeras. El análisis comparativo corroboraba que la desalación provocaba los mayores niveles de emisión de $\mathrm{CO}_{2}$, debido al mayor consumo eléctrico que se requiere para las fases de producción $\left(3,8 \mathrm{Kwh} / \mathrm{m}^{3}\right)$ y transporte $\left(1,3 \mathrm{Kwh} / \mathrm{m}^{3}\right)$. (Ver Cuadro 1). También se hacían notar los riesgos ambientales que plantea la desalación por los vertidos de salmuera y los posibles efectos de los trasvases sobre las cuencas receptoras por la incorporación de aguas con rasgos químicos y biológicos diferentes.

Descartada la desalación masiva se valoraron de nuevo las alternativas de transferencia analizadas en la documentación técnica del Plan Hidrológico Nacional, distinguiendo, según trazado y cuencas cedentes, dos grandes grupos: a) Un bloque de trasvases de recorrido próximo a la costa mediterránea, con origen en el Bajo Ebro y Ródano, que transferiría recursos a las Cuencas Internas de Cataluña, Comunidad Valenciana, Murcia y Almería; y b) Otro grupo de trasvases que seguiría un recorrido interior para cruzar ambas mesetas, aprovechando en la meridional el acueducto Tajo-Segura, con puntos de toma en Duero y Tajo, y entrega en áreas de uso de Alicante, Murcia y Almería, que se completaría con transferencias del Ebro o Ródano hacia Cataluña y Comunidad Valenciana.

Las alternativas de trasvase con origen en el río Tajo merecieron una valoración menos favorable, argumentada por una serie de motivos que aludían a la mayor irregularidad de las aportaciones de la cuenca, la deficiente calidad de los recursos si la toma se ubicaba aguas abajo de la confluencia del Jarama, las posibles afecciones de caudales sobre el Tiétar, la incidencia ambiental de las obras, afecciones sobre la producción hidroeléctrica y las exigencias del Convenio de Albufeira (1998) suscrito con Portugal para el aprovechamiento de los ríos ibéricos transfronterizos. Algunos de estos mismos inconvenientes se repetían en la opción del Duero, aunque ésta obtenía una mejor evaluación por el mayor nivel de 


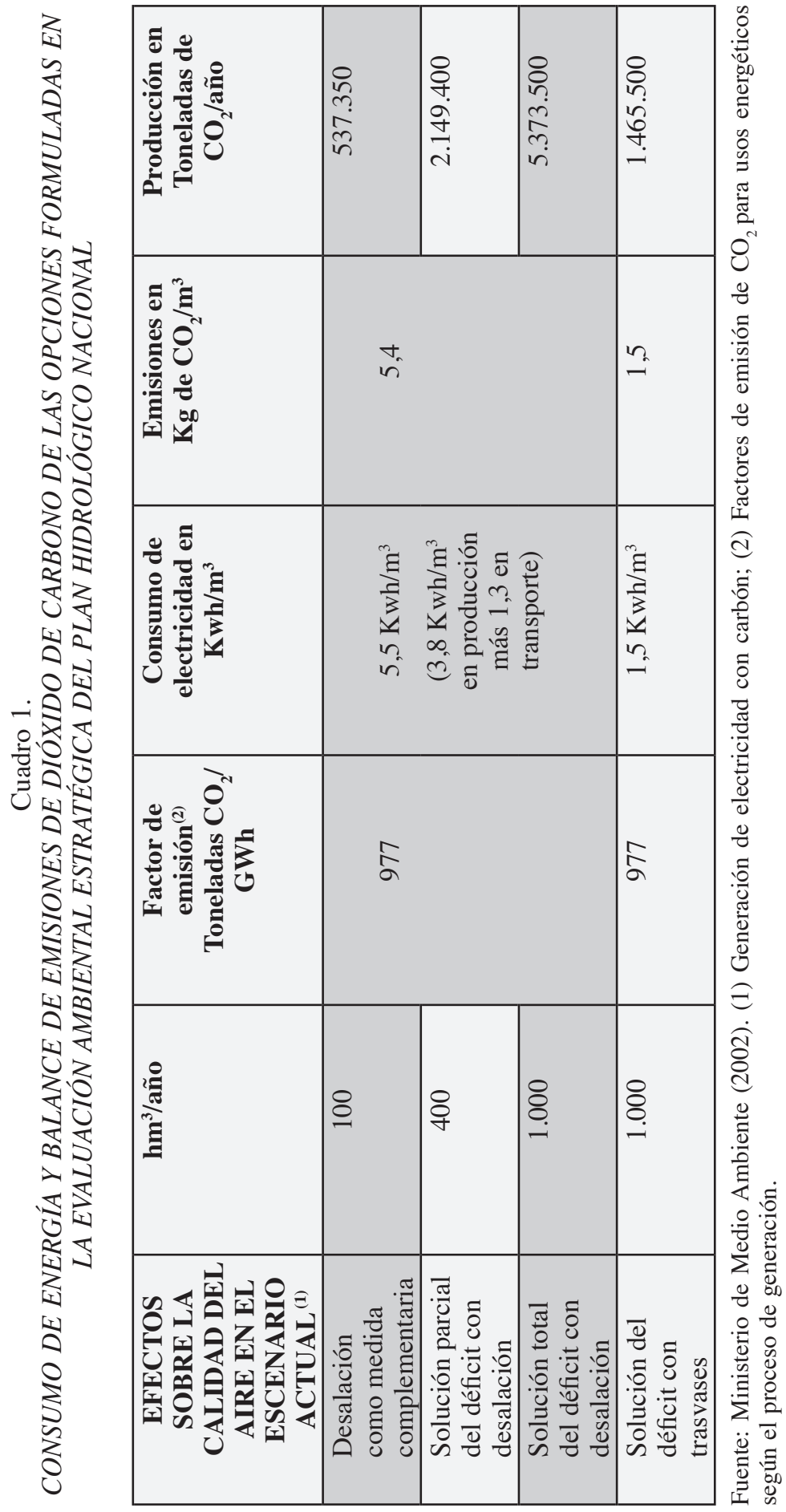


calidad y garantía de los recursos a transferir, sobre todo si se combinaba con otro trasvase desde el Ebro a Cataluña y Comunidad Valenciana. Esta solución mixta tendría en su contra el mayor coste de suministro, que se elevaría a $0,40 \square / \mathrm{m}^{3}$, frente a la opción de un trasvase único desde el Bajo Ebro a $0,31 \square / \mathrm{m}^{3}$. Sin embargo, la opción Duero-Ebro ofrecía ventajas apreciables como la mejor calidad del agua del Duero, con una conductividad de $417 \mu \mathrm{S} / \mathrm{cm}$, frente a los $1.028 \mu \mathrm{S} / \mathrm{cm}$ del Ebro, e incrementaba la garantía de suministro al combinar dos tomas distintas, que además reducían la posible incidencia sobre el Delta del Ebro. También fue evaluada otra alternativa mixta con transferencias desde el Ebro y Ródano, que obtuvo incluso una valoración final más alta que la solución Duero-Ebro.

Finalmente, la alternativa que mereció una mejor valoración fue la transferencia del Ebro, aunque se subrayaba la posible incidencia del trasvase sobre el Delta del Ebro como principal amenaza. Por dicho motivo, el capítulo 7 de la Evaluación Ambiental Estratégica del Plan Hidrológico Nacional dedicaba 47 páginas a la «Evaluación e integración ambiental del P.H.N. en la cuenca cedente: Directrices para el Plan Integral del Delta del Ebro». Dicho capítulo valoraba la situación actual del Delta del Ebro, a efectos de establecer las condiciones necesarias para garantizar su integridad y conservación. Reviste especial interés el apartado que analiza el régimen fluvial del Bajo Ebro y su incidencia en la conservación y dinámica hidrogeomorfológica del Delta, profundamente alterada desde la construcción del sistema de embalses Mequinenza-Ribarroja-Flix, que ha provocado una fuerte retención de los aluviones, la interrupción del flujo sedimentario y una regulación del flujo de caudales medios mensuales con notorias oscilaciones diarias motivada por el aprovechamiento hidroeléctrico de dichos reservorios. Nada se dice, en cambio, sobre la incidencia que ha tenido, sobre la reducción de la ablación, la recuperación de la cubierta vegetal en las vertientes ibérica y pirenaica conseguida durante la segunda mitad del siglo XX. Estos factores explicarían la drástica reducción de sedimentos en suspensión aportados por el Ebro a su Delta, que en la actualidad sería inferior al $5 \%$ del volumen que llegaba a principios de la pasada centuria. En este caso, se hace notar que la repercusión del trasvase del Ebro sobre el flujo sedimentario «es prácticamente nula, al no precisar la construcción de nuevos embalses en la cuenca». Por otro lado, se señalaba que el impacto ambiental sobre el tramo final del Ebro asociado al avance de la cuña salina podría considerarse muy moderado y susceptible de corregirse mediante una gestión apropiada de los embalses de Mequinenza, Ribarroja y Flix. Igualmente, tampoco se preveía impacto ecológico apreciable fuera del propio curso fluvial del Ebro, ya que gran parte del funcionamiento hidrodinámico del Delta estaría determinado por los caudales circulantes por los canales de riego, que están garantizados por el Plan Hidrológico Nacional. En líneas generales, se concluía que el trasvase no afectaría a ninguna de las unidades ambientales del Bajo Ebro ni a los ecosistemas asociados, subrayando además la oportunidad histórica que suponía la elaboración y aplicación del Plan Integral de Protección del Delta para garantizar su conservación (MMA, 2002).

En octubre de 2003, la Secretaría General de Medio Ambiente formuló la declaración de impacto ambiental sobre el proyecto de transferencias autorizadas por el artículo 13 de la Ley 10/2001, de 5 de julio, del Plan Hidrológico Nacional (BOE, nº 262, 1 de noviembre de 2003). En esa fecha no se había aprobado todavía el Plan Integral del Delta del Ebro, pero la declaración de impacto ambiental contenía ya los primeros avances de los estudios técnicos realizados para la protección del delta, como el régimen de caudales ambientales, que contemplaba un programa de crecidas controladas para el tramo final del río. La propuesta incluía dos crecidas controladas al año, una en primavera, con $600 \mathrm{~m}^{3} / \mathrm{s}$ de punta y 36 horas de duración, y otra hacia finales de otoño con máximo de $1.200 \mathrm{~m}^{3} / \mathrm{s}$ y 48 horas de duración. Según se indica en dicha declaración de impacto ambiental, los resultados que 
arrojaban los estudios técnicos para la protección del Delta no cuestionaban la viabilidad de la transferencia del Ebro. En la declaración de impacto también se observaban las máximas cautelas ambientales para la protección de la fauna y flora afectada por las obras, tanto en la zona de toma como en el recorrido, y se establecían sistemas de vigilancia y control de especies invasoras como el mejillón cebra, con la participación de expertos del Consejo Superior de Investigaciones Científicas.

\subsection{Un balance de luces y sombras del Plan Hidrológico Nacional}

Los documentos que antecedieron a la aprobación del Plan Hidrológico Nacional, más los informes complementarios realizados posteriormente por los técnicos del Ministerio de Medio Ambiente constituyeron un ejemplo de trabajo serio, sólido, ponderado, con propuestas equilibradas, ajeno a todo planteamiento político, demográfico o simplista. No obstante, no supone que toda la información manejada esté libre de aspectos menos logrados como, por ejemplo, las referencias históricas y consideraciones climáticas, manifiestamente mejorables unas y otras. Tampoco se valoró adecuadamente la posibilidad de plantear soluciones fragmentadas, con transferencias de pequeño recorrido que movilizaran también recursos sobrantes del Duero y Tajo, lo que polarizó toda la atención de los colectivos antitrasvasistas en la defensa del río Ebro para abortar cualquier tipo de transferencia, fuera o no viable. Por otro lado el Ministerio de Medio Ambiente tampoco desarrollo ninguna campaña de divulgación pública para explicar la tramitación, objetivos y obras previstas en el Plan, permitiendo con ello que la visceralidad y la ausencia de rigor técnico contaminase un debate donde primó el enfrentamiento entre territorios, con marginación del interés general y de una perspectiva nacional. Asimismo, conviene citar por excesivas, las concesiones en materia de inversiones, más que a determinadas cuencas hidrográficas, a las comunidades autónomas correspondientes, tal y como se hace muy patente en el Art. 36.3 y disposiciones adicionales de la Ley 10/2001 (Gil, A. y Rico, A. 2008 b). El Plan también fue objeto de críticas por el tratamiento que se hacía de la documentación económica (costes y beneficios derivados) y por mantener un modelo «estructuralista de oferta» vigente durante todo el siglo XX, basado en la construcción de grandes obras hidráulicas (Arrojo, P. 2001).

En cuanto a las cuencas receptoras, como se ha hecho notar, la propia Ley del Plan Hidrológico Nacional (2001) y la Evaluación Ambiental Estratégica (2002) enfatizaron las medidas de integración y protección ambiental, abandonando viejos planteamientos de oferta y fomento de los usos del agua (Melgarejo, J., 2004). En efecto, uno de los objetivos ambientales era evitar la sobreexplotación de acuíferos mediante la sustitución de extracciones con aguas trasvasadas, y para ello se exigía que los usuarios habían de disponer de «las concesiones o de cualquier otro título suficiente que acredite el derecho a la utilización privativa de las aguas, debidamente inscritos en el Registro de aguas de la cuenca receptora» (Art. 17.3). La Ley 10/2001, del Plan Hidrológico Nacional, puso especial énfasis en los objetivos de reequilibrio hidrológico y de sostenibilidad, prohibiendo la expansión del regadío con aguas trasvasadas en las cuencas receptoras (Art. 17.2), señalando que «en ningún caso podrán destinarse las aguas trasvasadas a la creación de nuevos regadíos, ni a la ampliación de los existentes en las zonas beneficiadas por las transferencias». En cambio, no se indicaba ninguna medida para otras Confederaciones Hidrográficas, incluida la del Ebro, donde siguen vigentes aspiraciones históricas de nuevas transformaciones en regadío que entran en profunda contradicción con la Agenda 2000 y la Reforma Intermedia de la PAC iniciada en junio de 2003, que es desarrollada por el Reglamento CE n ${ }^{\circ} 1782 / 2003$, del Consejo, de 29 de septiembre de 2003. Durante la última década, ha cambiado la percepción tradicional de la eficiencia del regadío, al evidenciarse que hay producciones agrarias que 
no son competitivas en los mercados internacionales sin las ayudas a la producción y a la exportación. Con ello, la expansión de nuevos regadíos no podría justificarse en muchos casos con argumentos socioeconómicos ni ambientales, ya que al incremento del consumo de agua se uniría un aumento de las producciones dependiente de las ayudas de la PAC.

El Plan Hidrológico Nacional no estableció, en cambio, ninguna directriz territorial dirigida a ordenar o limitar, en su caso, los abastecimientos con aguas trasvasadas. El plan establece que los títulos de aprovechamiento «podrán corresponder tanto al propio núcleo afectado como al sistema o entidad de abastecimiento en que se incluya este núcleo» (Art. 17.4). Sin embargo, debe resaltarse que la Ley 10/2001 incluyó el Artículo 30, sobre «Gestión eficaz de las aguas para abastecimiento», que prevé la colaboración entre las diferentes administraciones para promover medidas de la gestión de la demanda. No se hacía referencia a la ordenación del territorio ni al planeamiento urbanístico en relación con las transferencias de agua previstas para abastecimientos, y ello a pesar de que éstos acapararían el $44 \%\left(462 \mathrm{hm}^{3} /\right.$ año $)$ del volumen total $\left(1.050 \mathrm{hm}^{3} / a\right.$ ño) que se preveía trasvasar a Barcelona, Comunidad Valenciana, Murcia y Almería.

La Ley 10/2001, del Plan Hidrológico Nacional, también asumió implícitamente, en aras de la concordia, la patrimonialización fáctica del agua por parte de las Comunidades Autónomas, que se evidencia tanto en el sistema de reparto de la llamada cuota ambiental como en las disposiciones adicionales y, sobre todo, en el Artículo 36, que hace referencia al Anexo II y, en especial, de forma expresa y reiterada, a la Resolución del Pleno de las Cortes de Aragón de 30 de junio de 1992, conocida como «Pacto del Agua de Aragón». En este caso, aceptó íntegramente todas las demandas de obras hidráulicas solicitadas por los aragoneses, supeditando incluso la construcción del trasvase del Ebro a que todas las actuaciones del Pacto del Agua se encontraran concluidas o en fase de realización, entre las cuales se hallarían embalses reguladores que podrían tener un alto impacto ambiental como Biscarrués, Loteta o el recrecimiento de Yesa. Las presiones políticas de las comunidades autónomas también se dejó sentir en la modificación sustancial que se aplicó a la llamada cuota ambiental en la fase de tramitación parlamentaria. Así, en vez de ser el Organismo de Cuenca del Ebro el que administrase estas compensaciones atendiendo a prioridades hidráulicas y ambientales, tras la modificación del artículo 23.3, se dejó la puerta abierta a que fuesen las comunidades autónomas las que administren ese tributo. Con ese cambio se hubiese favorecido especialmente a Cataluña, sin duda como resultado del apoyo condicionado de CIU al Plan Hidrológico Nacional, ya que para establecer el reparto regional de la compensación $\left(0,03 \square / \mathrm{m}^{3}\right)$ ambiental por el trasvase del Ebro, el citado Art. 23.3 también señalaba que «se tendrá en cuenta el ámbito territorial en el que se produzca la misma» (Melgarejo, J. 2002).

\section{Las Comunidades Autónomas de Murcia y Valenciana en el Plan Hidrológico Nacional}

Aunque uno de los ejes básicos de la Ley 10/2001 del Plan Hidrológico Nacional fueron las transferencias de agua entre ámbitos territoriales de distintos planes de cuenca, como una solución prevista en la Ley de Aguas (Art. 45.1 T.R.L.A), debe subrayarse que la ley también presta atención a las necesidades en infraestructura hidráulica de todos los ámbitos de planificación. Estas actuaciones fueron recogidas en el Anexo II de la ley del Plan Hidrológico Nacional, con un listado de inversiones públicas que asciende a más de 22.600 millones de euros. Este programa fue informado favorablemente por el Consejo Nacional del Agua, el 30 de enero de 2001, con un coste de 18.853 millones de euros, sin contabilizar el presupuesto del trasvase del Ebro (3.770 millones de euros). Más del $84 \%$ 
de la inversión iba dirigida a incrementar el ahorro, la eficiencia y la racionalidad en el de agua, o para actuaciones de marcado carácter ambiental que pretenden primar los objetivos hidrológicos sobre los hidráulicos. Además de la partida de inversiones destinada a la realización de trasvases, se preveían otros ejes de inversión: modernización de regadíos, 32,6 \%; mejora de abastecimientos urbanos, $15 \%$; restauración hidrológico forestal, 9,9\%; regulación general, 14,4 \%; saneamiento y depuración, 13,8 \%; actuaciones en cauces para prevención de avenidas, 7,6 \%; control de calidad de aguas epigeas y subterráneas, 6,7 \% .

Una etapa fundamental previa a la elaboración del Plan Hidrológico Nacional fue la aprobación de los planes hidrológicos del Norte II, Norte II, Norte III, Duero, Tajo, Guadiana I, Guadiana II, Guadalquivir, Sur, Segura, Júcar, Ebro y cuencas intracomunitarias de Cataluña, mediante el Real Decreto 1664/1998, de 24 de julio. Los Planes de Cuenca del Segura y Júcar, que abarcan gran parte del territorio de las Comunidades Autónomas de Murcia y Valenciana, establecieron la necesidad de recurrir a transferencias desde otros ámbitos de planificación para dar respuestas a problemas ambientales y de escasez de recursos que amenazan usos del agua de gran trascendencia social y económica. Dichos planes programaron un gran número de actuaciones en territorio de las regiones de Murcia y Valencia para optimizar los recursos propios e incrementar su disponibilidad, garantizar demandas, ahorro de agua y modernización de regadíos y abastecimientos, gestión de sequías e inundaciones, incremento de fuentes no convencionales (residuales depuradas y desaladoras), redes de de control en acuíferos sobreexplotados, sistemas automáticos de información hidrológica (SAIH), conservación del patrimonio hidráulico, entre otras muchas medidas. Las actuaciones específicas planteadas en los citados planes para las regiones de Murcia y Valencia estaban próximas a dos centenares y, además, faltaría incluir las obras previstas en el marco de políticas generales de modernización de regadíos, abastecimientos, saneamiento y depuración. En conjunto, para acometer todas las actuaciones previstas en los Planes Hidrológicos de Cuenca del Segura y Júcar para sus respectivas demarcaciones territoriales, se habían presupuestado obras por valor aproximado de 5.375 millones de $\square$. En la fecha de aprobación definitiva del Plan Hidrológico Nacional (2001), algunas de las realizaciones hidráulicas planteadas en los Planes de Cuenca (1997) ya se habían completado y otras estaban en fase de ejecución, como ocurría con la conexión Júcar-Vinalopó. Por dicho motivo, no existe una total coincidencia en el listado de obras que incluyó el Anexo II de Inversiones de la Ley 10/2001, de 5 de julio, del Plan Hidrológico Nacional, para las demarcaciones del Segura y Júcar con las inversiones programadas en los respectivos Planes de Cuenca, aunque las diferencias resultan mínimas.

El Plan Hidrológico Nacional preveía una inversión de 1.066 millones de $\square$ en Murcia y 1.305 millones de $\square$ en la Comunidad Valenciana, y ello sin incluir el coste de la transferencia del Ebro. Se otorgó una atención prioritaria a la construcción de nuevas presas para laminación de avenidas, completadas con el acondicionamiento de cauces y otras medidas contra el riesgo de inundaciones. En la cuenca del Segura se incluyeron 34 actuaciones que han servido para completar los Planes de Defensa de Avenidas de 1977 y 1987, entre las cuales destacan las presas previstas sobre las ramblas de Lébor, Torregorda, Seca Salada, la Risca, Puerto del Garruchal, Moratalla, rambla Salada, Puerto de la Cadena, Tabala y Arroyo Grande, y el recrecimiento de Camarillas y Valdeinfierno. También se han previsto obras hidráulicas para el encauzamiento de colectores urbanos y fluviales, completados con interceptores de pluviales, como los propuestos para Cartagena, y correcciones hidrológicas y forestales en cabeceras de ramblas y barrancos (Benipila y Albujón). Un esfuerzo de inversión similar se planteaba en la demarcación del Júcar, con actuaciones de gran trascendencia para la reducción del riesgo de inundaciones, como la terminación de la presa de Tous y la construcción de otras nuevas como las de Villamarchante, Sellent, Montesa y 
Marquesado. En el apartado de acondicionamiento de cauces para la laminación de avenidas, se plantean actuaciones: en los ríos Júcar y Turia; en los barrancos de Carraixet, Torrente, Chiva, Pozalet y Ovejas; mejora de drenajes en la marjal sur del Júcar y en los ríos Vaca y rambla de Gallinera; encauzamientos de colectores urbanos, algunas ya realizadas como la del río Seco en Castellón, estructuras de laminación y correcciones hidrológico-forestales (rambla de Gallinera, río Serpis, barranco de las Ovejas).

Asimismo, se priorizó la vertiente de los sistemas de alerta y previsión (SAIH) y la delimitación del Dominio Público Hidráulico a través del proyecto LINDE. Cabe recordar que a partir de 1989 las Confederaciones Hidrográfica del Segura y del Júcar, respectivamente, fueron las primeras cuencas de España en disponer de Sistemas Automáticos de Información Hidrológica (SAIH). Su ampliación y explotación mereció atención prioritaria en el Plan Hidrológico Nacional, al igual que el programa LINDE, para la delimitación del Dominio Público Hidráulico, con la zonificación de cauces y márgenes fluviales, fijando las zonas de servidumbre $(5 \mathrm{~m})$ y de policía $(100 \mathrm{~m})$.

Otro apartado fundamental son las obras para modernización de regadíos, que beneficiarían en Murcia al Valle del Guadalentín, Vega Alta y Vega Media del Segura, y en la Comunidad Valenciana a la Vega Baja del Segura, Plana de Castellón o Acequia Real del Júcar. Una parte de estas inversiones han sido realizadas por el Ministerio de Agricultura, al amparo de las ayudas previstas en el Plan Nacional de Regadíos (Real Decreto 329/2002), que han sido gestionadas a través de las Sociedades Estatales de Infraestructuras Agrarias (S.E.I.A.S.A.) del Sur y del Este. Asimismo, en esta materia resulta obligado resaltar la importante labor desarrollada por las propias Comunidades Autónomas de Murcia y Valenciana, que sitúan a las respectivas regiones entre las primeras de España en difusión de riegos localizados y modernización de regadíos. Durante el periodo 1992-2005, las ayudas de la Ley 47/1987 de la Generalidad Valenciana han permitido convertir en riego localizado unas 158.000 ha, mientras que las proporcionadas por el Ministerio de Agricultura a través de las Sociedades Estatales de Infraestructuras Agrarias (S.E.I.A.S.A.) han auspiciado la modernización de otras 40.000 ha. Durante el periodo 2001-2007, la Comunidad Autónoma de la Región de Murcia también ha desarrollado 11 actuaciones de modernización de regadíos, mediante 3 Convenios de Colaboración suscritos con el Ministerio de Agricultura y otros 8 con S.E.I.A.S.A. del Sur y del Este, que han supuesto una inversión de 35,4 millones de $\square$ y han propiciado la modernización de 51.590 hectáreas. Por otro lado, durante ese mismo periodo, la Consejería de Agricultura de la Región de Murcia ha invertido otros 34,3 millones de $\square$ en 45 obras de mejora y consolidación de regadíos, que han incluido la construcción de embalses, redes a presión, cabezales de filtrado, tomas de riego con hidrantes, sistemas para recogida de pluviales, suministro con recursos no convencionales, entre otras actuaciones, que han beneficiado a 40 entidades, con 32.632 regantes y 79.521 hectáreas.

En materia de saneamiento, depuración y reutilización de residuales, se planteaban una decena de actuaciones, en Novelda, Monforte del Cid, Benidorm, Rincón de León (Alicante), Alcira, Algemesí, Sueca o la depuración integral para la Albufera sur. Igualmente, el esfuerzo coordinado de la administración estatal y la regional para impulsar iniciativas de reutilización de residuales ha permitido que las Comunidades Autónomas de Murcia y Valenciana se sitúen en una posición de liderazgo en España. La región de Murcia reutiliza alrededor de $100 \mathrm{hm}^{3} /$ año, que supone la práctica totalidad del agua residual regenerada, y por volumen reutilizado la Comunidad Valenciana ocupa una posición cimera en España, al aprovechan unos $235 \mathrm{hm}^{3} /$ año, de los cuales unos $165 \mathrm{hm}^{3} /$ año corresponden a reutilización directa y el resto a indirecta. En 2006 la Generalidad Valenciana ha desarrollado varios proyectos de incorporación de tratamiento terciario en grandes plantas depuradoras de Valencia (Pinedo) y de Alicante (Benidorm, Torrevieja, Orgegia y Rincón de León), 
que elevarán el volumen de reutilización directa a más de $300 \mathrm{hm}^{3} / \mathrm{año}$. Por ejemplo, en la planta del Rincón de León, que alimenta de residuales a los regadíos del Campo de Alicante y Vinalopó, se ha implantado un sofisticado sistema de tratamiento terciario, con desalación mediante ósmosis inversa, para producir $25.000 \mathrm{~m}^{3} /$ día de agua desalada más otros $13.000 \mathrm{~m}^{3} /$ día de agua ultrafiltrada. Aunque el agua obtenida también se destinará al riego de parques y jardines de la ciudad de Alicante, tendrá como destino preferente su distribución a presión para el riego de 6.800 ha de las entidades Aralvi y Agricoop, en el Campo de Alicante y Medio Vinalopó, y otras 7.000 ha de la Comunidad de Riegos de Levante en el municipio de Elche, a un coste que no excederá los $0,10 \square / \mathrm{m}^{3}$.

En el apartado de desalación, se plantearon 5 nuevas desaladoras (Campo de Cartagena, Murcia, Alto Guadalentín, La Pedrera, Pilar de la Horadada), 2 nuevas desalobradoras en Vega Baja y Guadalentín y la ampliación de las plantas de la Mancomunidad de Canales del Taibilla en Murcia y Alicante. El Plan Hidrológico Nacional también concedió atención prioritaria a la realización de la conexión Júcar-Vinalopó, la construcción del túnel Talave-Cenajo y la modernización de conducciones como el canal Júcar-Turia, la Acequia Real del Júcar o el canal del Campo de Turia. Estas actuaciones se completaban con otras inversiones que potencian las redes de control y seguimiento de calidad de las aguas, las correcciones hidrológico-forestales y la mejora de los abastecimientos de agua potable, con diferentes actuaciones que beneficiaban a la Mancomunidad de los Canales del Taibilla y los abastecimientos de Albacete, Manchuela y Valencia.

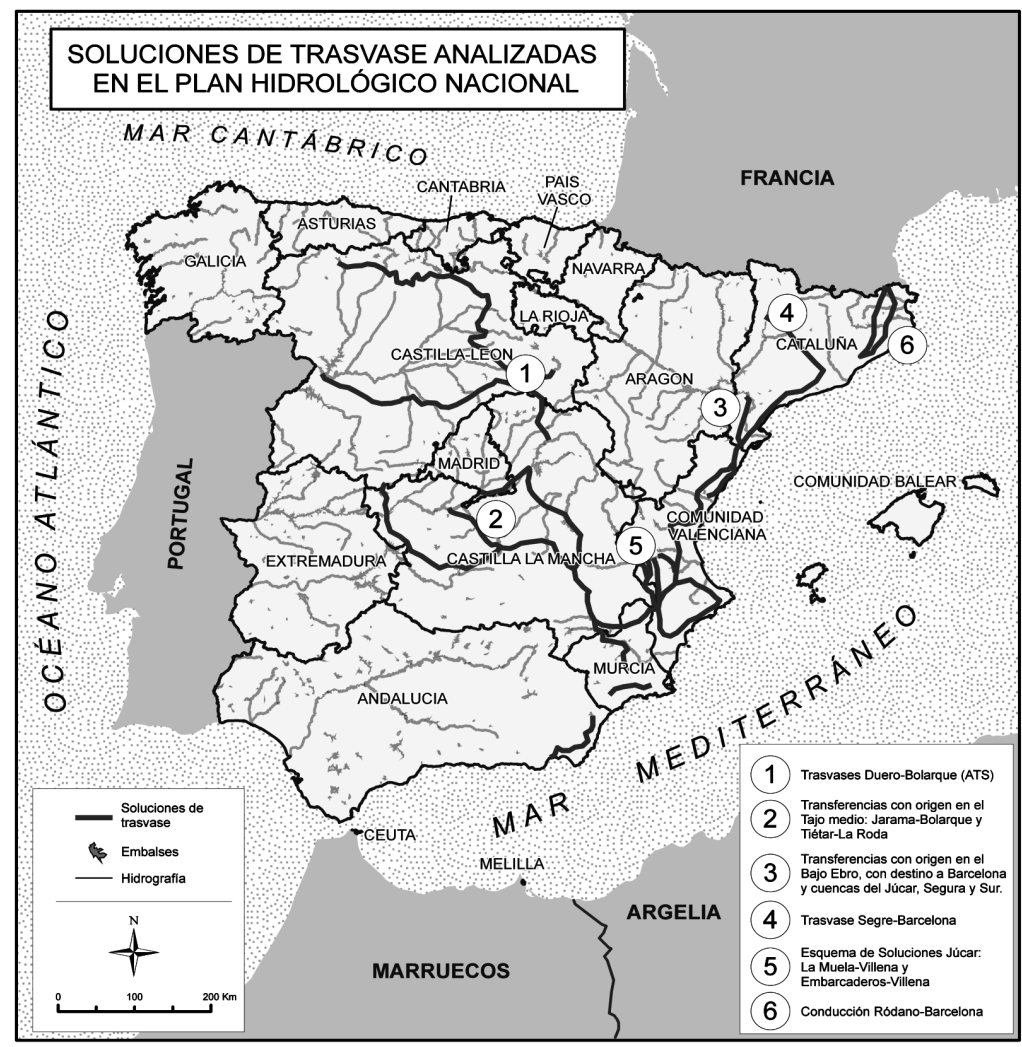


Empero, el eje central del Plan Hidrológico Nacional fue la regulación de los trasvases de agua entre diferentes ámbitos de planificación, y ello situaba a las regiones de Murcia y Valencia como territorios beneficiarios de las transferencias previstas en la Ley 10/2001, con origen en el Bajo Ebro y destino en las cuencas deficitarias del Júcar y Segura. Al igual que sucedió con el Anteproyecto de Plan Hidrológico Nacional de 1993, los trasvases volvieron a suscitar la denominada «guerra del agua» que, con marcado carácter político, enfrentaba a los gobiernos autonómicos que habrían de ceder agua con las comunidades beneficiarias de dichas transferencias. Tras diversos estudios de viabilidad técnica, económica y ambiental, y atendida la opinión ampliamente mayoritaria del Consejo Nacional del Agua, el Ministerio de Medio Ambiente optó por la transferencia de aguas del Ebro, con un coste total de 3.770 millones de euros. El trasvase tendría origen pasado Flix, en el Bajo Ebro, y como destinos Barcelona (190 hm³/año), cuenca del Júcar (315 hm³/año), cuenca del Segura $\left(450 \mathrm{hm}^{3} / \mathrm{año}\right)$ y Almería (95 hm³/año). Por parte del Ministerio de Medio Ambiente, se adujeron sus menores costes ambientales y económicos, y la existencia de sobrantes, con más de $10.000 \mathrm{hm}^{3} / a$ ño vertidos al Mediterráneo. Nada se decía, en cambio, de una gran ventaja de esta transferencia sobre otras opciones, como es el menor riesgo de sequía del Ebro gracias a las aportaciones de sus tributarios pirenaicos.

Es de advertir que las transferencias del Ebro previstas en el Plan Hidrológico Nacional (2001) se redujeron notablemente respecto al Anteproyecto de Plan Hidrológico de 1993, donde se proponían $1.855 \mathrm{hm}^{3} /$ año, en contraste con los 1.050 que fueron finalmente aprobados por ley. Así, el Júcar recibiría $315 \mathrm{hm}^{3} /$ año en lugar de 575 , las cuencas internas de Cataluña $190 \mathrm{hm}^{3} /$ año en vez de 475 y la del Segura 450 frente a los $805 \mathrm{hm} /$ año previstos en 1993 (Gil, A. 1995). Descontadas las pérdidas en transporte de $50 \mathrm{hm} 3 /$ año, el volumen neto a transferir asciende a $1.000 \mathrm{hm}^{3} /$ año, de los cuales 439 tendrían un uso urbano e industrial, y los restantes 560 se emplearían para atender problemas de sobreexplotación de acuíferos e infradotación de regadíos. Por cuencas receptoras, venía en cabeza la del Segura, con un volumen neto de $430 \mathrm{hm}^{3} /$ año, seguida del Júcar (300 hm³/año), cuencas internas de Cataluña (190 hm³/año) y Almería (90 hm³/año) (Ver Cuadro 2). La región de Murcia accedería a un volumen aproximado de $380 \mathrm{hm}^{3} /$ año, que resultan estratégicos para garantizar usos agrarios, urbanos e industriales de gran trascendencia socioeconómica. Estos usos son muy vulnerables a episodios de sequía en la cuenca del Segura, sobre todo cuando afectan también a la cabecera del Tajo. En este caso, la transferencia del Ebro podría suplir los fallos de suministro que padecen durante los episodios de sequía las áreas destinatarias del trasvase Tajo-Segura y estabilizaría el sistema de explotación general de la Cuenca del Segura. Además, conviene resaltar los beneficios ambientales de la trasferencia, ya que permitiría resolver los graves problemas de sobreexplotación de recursos subterráneos que sufren 20 sistemas acuíferos, 3 de ellos compartidos con la Cuenca del Júcar (Jumilla-Villena, Serral-Salinas y Sierra de Crevillente), por bombeos de reservas no renovables que la propia Confederación Hidrográfica del Segura estima que pueden superar $300 \mathrm{hm}^{3} /$ año (CHS, 2008).

Por otro lado, la transferencia del Ebro elevaría la garantía de suministro, de unas 350.000 ha de regadíos intensivos de Castellón, Alicante, Murcia y Almería, con una dotación media cercana a $1.300 \mathrm{~m}^{3} / \mathrm{ha} / \mathrm{año}$, que se hubiese completado con otras actuaciones complementarias previstas en la Ley 10/2001, del Plan Hidrológico Nacional, para reutilización de residuales y desalación de aguas salobres. La Comunidad Valenciana se habría beneficiado de las transferencias previstas para el Júcar y, en parte, Segura, con un volumen que excedería los $350 \mathrm{hm} 3 /$ año. Con estos recursos, más los aportados por fuentes no convencionales, se habrían atendido problemas de sobreexplotación de acuíferos, intrusión marina e infradotación de regadíos, además de garantizar los abastecimientos de agua potable en las planas costeras de Castellón, Vinalopó, Campo de Alicante y Bajo Segura. 
Cuadro 2

USOS PREVISTOS PARA LAS AGUAS DEL TRASVASE DEL EBRO EN LAS CUENCAS RECEPTORAS $\left(H M^{3} / A \tilde{N} O\right)$

\begin{tabular}{|l|c|c|c|c|c|}
\hline $\begin{array}{c}\text { Cuenca } \\
\text { receptora }\end{array}$ & $\begin{array}{c}\text { Urbano e } \\
\text { industrial } \\
\mathbf{h m} \text { /año }\end{array}$ & $\boldsymbol{\%}$ & $\begin{array}{c}\text { Regadío } \\
\mathbf{h m} \text { /año }\end{array}$ & $\boldsymbol{\%}$ & $\begin{array}{c}\text { Total } \mathbf{h m}^{\mathbf{3}} / \\
\mathbf{a n ̃ o}\end{array}$ \\
\hline Júcar & 159 & 53 & 141 & 47 & 300 \\
\hline Segura-Almería & 100 & 20 & 420 & 80 & 520 \\
\hline Barcelona & 180 & 100 & - & - & 180 \\
\hline Total & 439 & 44 & 561 & 56 & 1.000 \\
\hline
\end{tabular}

Fuente: Plan Hidrológico Nacional, Análisis Económico, 2000.

El coste total del trasvase del Ebro, cuyas obras se pusieron en marcha a principios de 2004, ascendía a 3.770 millones de euros, con anualidades de 329,8 millones. De los gastos anuales, 175,4 millones de euros correspondían a la amortización de las obras y 154,4 millones a costes de explotación, administración y mantenimiento; estos últimos se descomponían en 66,7 de coste energético, 45,2 para mantenimiento y administración, 10,8 de afecciones y 31,5 millones para compensaciones ambientales a la cuenca cedente. Sin incluir ayudas económicas y con la amortización íntegra de las obras el trasvase del Ebro por parte de los usuarios, se garantizaba una gran racionalidad económica en la ejecución y explotación del proyecto, con costes medios de $0,30 \square / \mathrm{m}^{3}$ (Melgarejo, J. 2004). Con la contribución de ayudas estatales y de fondos estructurales de la Unión Europea, los costes medios se habrían reducido a menos de $0,24 \square / \mathrm{m}^{3}$. Además, frente al agua para riego, los suministros de agua potable podrían asumir una mayor carga financiera en la amortización de las obras por la prioridad de uso que les asiste, lo que garantizaba que las tarifas finales de explotación y amortización fuesen accesibles a todo tipo de usuarios. Así, el precio del agua para riego se habría reducido hasta tarifas próximas a las vigentes en otros trasvases, como el Tajo-Segura (Ver cuadro 3). En cualquier caso, son costes mucho más bajos que los de desalación de aguas marinas, y podían ser asumidos perfectamente por regantes y abastecimientos. Los costes de operación y bombeo que reflejaba la memoria técnica resultaban viables para la mayoría de usuarios, aunque se incrementasen en $0,03 \square / \mathrm{m}^{3}$

\section{Cuadro 3}

PROPUESTA DE PRECIO DE LAS AGUAS TRASVASADAS DEL EBRO CON DISCRIMINACIÓN SEGÚN USOS

\begin{tabular}{|c|c|c|c|c|}
\hline \multicolumn{2}{|c|}{ Precio medio } & \multicolumn{3}{|c|}{ Precio discriminado } \\
\hline Volumen & Precio & Uso & Volumen & Precio \\
\hline \multirow{3}{*}{$1.000 \mathrm{hm}^{3} /$ año } & $0,30 \square / \mathrm{m}^{3}$ & Regadío & $\begin{array}{c}561 \mathrm{hm} / \mathrm{año} \\
(56 \%)\end{array}$ & $0,15 \square / \mathrm{m}^{3}$ \\
& & Abastecimiento & $\begin{array}{c}439 \mathrm{hm}^{3} / \mathrm{año} \\
(44 \%)\end{array}$ & $0,49 \square / \mathrm{m}^{3}$ \\
\cline { 3 - 5 } & & & & \\
\end{tabular}

Fuente: Ródenas Cañada, M.A. y Guillamón Álvarez, J. 2005. 
para compensación ambiental a la cuenca del Ebro: a)en el tramo Ebro-Castellón Norte, rondarían los $0,033 \square / \mathrm{m}^{3}$; b)en las áreas de demanda de Castellón Norte-Mijares, Castellón Sur, Turia y Tous, alcanzarían precios finales entre 0,046 y $0,055 \square / \mathrm{m}^{3}$; c)los costes más altos se registrarían en el Alto Vinalopó $\left(0,12 \square / \mathrm{m}^{3}\right)$, al repercutir los costes de bombeo que se precisan para franquear el umbral de Fuente La Higuera, a 600 metros de altitud; d)y descenderían en el Bajo Segura $\left(0,066 \square / \mathrm{m}^{3}\right)$, al recuperar parte del coste energético con los ingresos obtenidos por turbinación.

Otra de las premisas ambientales establecida para el trasvase del Ebro era limitar la derivación de caudales de octubre a mayo, al objeto de aprovechar los ocho meses con mayor disponibilidad de sobrantes. Al mismo tiempo se garantizaban los caudales ambientales del Delta y la satisfacción de las demandas actuales y futuras de la cuenca. El trasvase del Ebro permite acceder, además, a recursos que cumplen con todos los requisitos de calidad exigibles a las aguas potables y, por supuesto, para uso agrícola. De hecho, durante el período de octubre a mayo, las aguas del Ebro en Tortosa ofrecen una calidad sensiblemente mejor a las del Júcar antes de su entrada en la Ribera, donde los retornos de riego y los vertidos de residuales las inutilizan para abastecimiento urbano. En efecto, en el trimestre de octubre a diciembre los valores medios de conductividad medidos en Tortosa (19802005), están comprendidos entre 1.052 y $1.072 \mu \mathrm{s} / \mathrm{cm}$; sin embargo, de enero a marzo, la conductividad siempre es inferior a $900 \mu \mathrm{s} / \mathrm{cm}$, y desciende a valores de 796 y $795 \mu \mathrm{s} / \mathrm{cm}$ en abril y mayo. Por otro lado, es preciso recordar que con estos mismos recursos de agua se alimenta, desde hace dos décadas, el ministrasvase del Ebro al Campo de Tarragona, mediante una presa situada a la altura de la población de Campredó, en el municipio de Tortosa, que deriva las aguas provenientes de los canales derecho e izquierdo del delta del Ebro. Este trasvase, que cuenta con $63 \mathrm{~km}$ de recorrido y $4 \mathrm{~m}^{3} / \mathrm{s}$ de capacidad, desempeña un papel fundamental para garantizar el suministro de agua potable a la capital tarraconense, a su complejo petroquímico, a los enclaves turísticos de la Costa Dorada y a diferentes municipios de las comarcas de Tarragona, Baix Camp, Baix Penedés y Conca de Barberá.

El proyecto y el estudio de impacto ambiental de las transferencias previstas en el artículo 13 de Ley 10/2001 del Plan Hidrológico Nacional fueron sometidos al trámite de información pública en junio de 2003. Sus rasgos técnicos más sobresalientes se resumen en un trazado con dos ramales, uno para Barcelona $\left(11 \mathrm{~m}^{3} / \mathrm{s}\right)$ y otro para el sur $\left(50 \mathrm{~m}^{3} / \mathrm{s}\right)$, que suman $914 \mathrm{~km}$ de recorrido, 12 estaciones de bombeo, $97 \mathrm{~km}$ de túneles, $331 \mathrm{~km}$ de canales, $472 \mathrm{~km}$ de tuberías y 22 embalses y depósitos reguladores. Para minimizar costes y afecciones al territorio, en su diseño se procuraba el mayor aprovechamiento posible de infraestructuras ya existentes como el canal Cherta-Calig, el postrasvase Tajo-Segura y el minitrasvase del Ebro a Tarragona. El ramal sur, diseñado para transportar $860 \mathrm{hm}^{3} / \mathrm{año}$, comprende $746 \mathrm{~km}$ de trazado; de los cuales, $395 \mathrm{~km}$ afectan a la Comunidad Valenciana, con capacidades de transporte que se reducen a medida que se entregan caudales, desde 50 $\mathrm{m}^{3} / \mathrm{s}$ en Castellón a $45 \mathrm{~m}^{3} / \mathrm{s}$ desde Tous al embalse de Azorín (Monóvar), y $32 \mathrm{~m} 3 / \mathrm{s}$ hasta el túnel del Saltador (Lorca) (Medina, A. 2004). Al tratarse de un trasvase con la toma ubicada cerca de la desembocadura del Ebro, el principal inconveniente del perfil longitudinal de este trazado es su consumo energético, sobre todo en el ramal sur que debía atender las áreas de uso de Alicante, Murcia y Almería, al tener que salvar con varios bombeos el interfluvio de la Costera- Alto Vinalopó, más de $600 \mathrm{~m}$ de altitud.

Aún así, este mismo factor no ha supuesto impedimento alguno para que el Ministerio de Medio Ambiente y Medio Rural y Marino y la propia Unión Europea hayan considerado viable el trazado modificado de la conexión Júcar-Vinalopó, con una eficiencia energética bastante inferior al trasvase derogado del Ebro, al tener que asumir una altura de bombeo de 767 metros de columna de agua. Asimismo, con una calidad del agua mermada por retornos 
urbanos y de riego, la conexión Júcar-Vinalopó tan sólo podrá atender ciertos consumos agrícolas en cultivos leñosos, en áreas de uso situadas entre los 550 y 240 m de altitud. En la Evaluación Ambiental Estratégica del Plan Hidrológico Nacional (2002), se valoró que el consumo energético de los trasvases de agua previstos como opciones estratégicas se elevaría a $1,5 \mathrm{kWh} / \mathrm{m}^{3}$, tras el balance de caudales turbinables y de bombeo. En el trasvase del Ebro, estimaciones posteriores han cuantificado la energía total de bombeo en 2.500 GWh y la producida por turbinación en $500 \mathrm{GWh}$, lo que arroja un consumo neto medio ponderado de $2 \mathrm{kWh} / \mathrm{m}^{3}$ (Ródenas, M.A. y Guillamón, J. 2005).

Las obras del trasvase se iniciaron el 18 de febrero de 2004, en Archena (Murcia) y Huercal Overa (Almería). El 25 de febrero se colocó la primera piedra del trasvase del Ebro en la Comunidad Valenciana, en la embocadura sur del túnel de Fuente la Higuera (Villena), por el entonces presidente del gobierno de España, vísperas de las elecciones generales de 14 de marzo de 2004. Éstas motivaron un cambio de signo político en el gobierno de la nación y, tras ello, el 18 de junio de 2004 se promulgó el Real Decreto Ley $2 / 2004$, que supuso la paralización inmediata de las obras del trasvase del Ebro y la anulación fáctica de las transferencias aprobadas en la Ley 10/2001, de 5 de julio, del Plan Hidrológico Nacional. La anulación del trasvase estaba incluida en el programa electoral del Partido Socialista, pero además fue exigida por diferentes colectivos políticos y antitrasvasistas de Cataluña y Aragón, que condicionaron su apoyo al nuevo gobierno a dicha abolición. Así, el 22 de junio de 2005 se promulgó la Ley 11/2005 de modificación de la Ley 10/2001, de 5 de julio, del Plan Hidrológico Nacional, y se derogó la transferencia del Ebro. En ningún momento se valoró la posibilidad de recurrir a soluciones intermedias o fragmentadas, aprovechando el trasvase en ejecución, y subsanando, si es que las había, posibles deficiencias técnicas del proyecto.

\section{La paralización de los trasvases en ejecución (Ebro y Júcar-Vinalopó) y la impo- sición del programa A.G.U.A.}

La Ley 11/2005, de 22 de junio, por la que se modifica la Ley 10/2001, de 5 de julio, del Plan Hidrológico Nacional (BOE $n^{\circ}$ 149, jueves 23 de junio de 2005) amplió los contenidos del Real Decreto Ley 2/2004, que motivó la paralización de las obras del trasvase del Ebro, reproduciendo la misma exposición de motivos, pero añadiendo más modificaciones a la Ley del Plan Hidrológico Nacional (2001) y al propio texto refundido de la Ley de Aguas (RD. 1/2001, de 20 de julio). En efecto, a través de una disposición final primera en la Ley 11/2005, se modifica el Artículo 2 de la Ley de Aguas para incluir las aguas procedentes de desalación dentro del dominio público hidráulico, lo que reserva el control sobre la concesión de nuevas plantas desaladoras al Estado. En la exposición de motivos de la Ley 11/2005, se pretendía justificar la derogación del trasvase del Ebro, esgrimiendo a las siguientes razones: a) la exageración de los beneficios económicos del proyecto y la falta de concreción de las tarifas resultantes para cada tipo de uso y destino; b) el análisis poco adecuado de las repercusiones ambientales del trasvase en el régimen del Ebro y su Delta; c) la ausencia de rigor en los estudios sobre la disponibilidad de agua en la cuenca cedente y sobre la capacidad de regulación de los embalses en las cuencas receptoras. Se señala que no se garantizaban los derechos de la cuenca cedente a disponer de más agua en el futuro, y también que no se aseguraba la obligatoria circulación de caudal ambiental aguas abajo de la derivación. Por todas estas supuestas deficiencias, se asevera que no existía posibilidad de obtener financiación comunitaria. Sin embargo, todas estas afirmaciones no se apoyaron en ningún documento técnico del propio Ministerio de Medio Ambiente que las corroborase. Sorprende también la alusión a deficiencias, ausencia de rigor, falta 
de información y otras, en los documentos que sustentaban la realización del trasvase del Ebro, en su mayoría realizados por los propios técnicos del Ministerio de Medio Ambiente en una actividad profesional de años.

La exposición de motivos está plagada de opiniones y juicios de valor que no se corresponden con la realidad. Por ejemplo, en la exposición de motivos de la Ley 11/2005, se afirma que la Directiva Marco de Aguas 2000/60/CE condiciona la realización de trasferencias entre cuencas a que previamente se hayan optimizado los recursos hídricos de cada una y al mantenimiento de los caudales que garanticen la calidad ecológica de las aguas. Lo cierto es que dicho requisito no es mencionado en ninguna de las 72 páginas que componen la citada Directiva, y tampoco en el artículo 13 ni en el Anexo VII que desarrollan los contenidos específicos de los planes hidrológicos de cuenca. En este sentido, la legislación española de aguas que emana de la Ley 29/1985, de 2 de agosto, resulta mucho más precisa y exigente que la propia Directiva en materia de trasvases, con unos principios de cautela ambiental claramente definidos en los planes hidrológicos de cuenca y en el propio Plan Hidrológico Nacional.

Por otro lado, se intenta instrumentar la necesidad de una «nueva política del agua» en España, aludiendo a las exigencias de la Directiva Marco de Aguas 2000/60/CE, a la que se cita con reiteración como uno de los motivos para derogar el trasvase del Ebro, cuando la citada norma europea no recoge ni un solo artículo que prohíba la realización de transferencias de agua entre cuencas. Igualmente se indica que la derivación de agua no garantizaría el caudal ambiental aguas abajo de la toma tal y como exige la Directiva Marco 2000/60/CE, cuando lo cierto es que el trasvase del Ebro asumía con creces el caudal ecológico establecido en el Plan Hidrológico de la Cuenca del Ebro (100 m³ $/ \mathrm{s})$. Además, para despejar cualquier duda sobre el caudal ecológico, en la disposición adicional décima de la Ley 10/2001, de 5 de julio del Plan Hidrológico Nacional, se establecía la obligación de elaborar un Plan Integral de Protección del Delta del Ebro (PIDE), donde se preveía la consulta y participación de la Generalidad de Cataluña y de los entes locales, con el objetivo de definir el régimen hídrico que permitiese el desarrollo de las funciones ecológicas del río, delta y ecosistema marino próximo. Inicialmente, según esa disposición adicional, la aprobación de dicho plan correspondía al gobierno de la nación, mientras que la reforma de la Ley del Plan Hidrológico Nacional, por la Ley 11/2005, establece que se aprobará «previo mutuo acuerdo» entre la Generalidad de Cataluña y el Estado. Esta norma, que determinará los caudales ecológicos del Ebro en el Delta, puede condicionar «aguas arriba» los usos del agua en toda la cuenca, lo que arroja serias dudas sobre su constitucionalidad, ya que su aprobación debería corresponder enteramente al Estado. Además, se advierte que podría contravenir la propia Directiva Marco de Aguas, que ha vuelto a insistir con énfasis en el criterio, vigente en España desde 1926, de gestionar los ríos por cuencas hidrográficas (Moreu, J. L., 2006).

La interpretación que se hace de la Directiva Marco de Aguas 2000/60/CE como fundamento de una «nueva política de aguas», no debe ocultar, sin embargo, serias deficiencias de su contenido. En efecto, en la misma se priman las cuestiones de calidad de las aguas, mientras se ignoran o infravaloran otros aspectos fundamentales como la propia gestión, la optimización de los recursos o los riesgos naturales asociados al agua (sequías e inundaciones). De hecho, su artículo 1 afirma que «el objeto de la Directiva es establecer un marco para la protección de las aguas superficiales continentales, las aguas de transición, las aguas costeras y las aguas subterráneas». Con esta orientación, sus contenidos esenciales se dirigen a resolver los graves problemas de calidad del agua y de degradación de los ecosistemas acuáticos y marinos que padecen los países del norte y centro de Europa. En cambio, la Directiva ignora problemas y realidades específicos de los países del Mediterráneo, como la 
optimización de recursos de agua, gestión de la demanda, garantía de suministros, trascendencia social y económica del agua, empleo de aguas desaladas, reutilización de residuales o la participación de comunidades de usuarios en la administración del agua. Igualmente, no dedica la más mínima atención ni prioridad a las sequías e inundaciones en ninguno de los 26 Artículos y los 10 Anexos que la componen, y la reutilización de residuales o la producción de aguas desaladas tan sólo son citadas en una ocasión en su Anexo VI (Parte B), aunque sin entrar en ningún tipo de detalle conceptual, técnico, ambiental ni de uso.

Para algunos ámbitos como el adscrito a la Confederación Hidrográfica del Júcar, que fue elegida cuenca piloto para la aplicación de la Directiva Marco, se han elaborado ya los informes relativos al impacto ambiental de la actividad humana y el análisis económico del agua (Art. 5), con un diagnóstico de las presiones que ejercerán los diferentes usos en 2015. Según el calendario de aplicación de la Directiva, en diciembre de 2006 tendría que haberse establecido una red de medida para el seguimiento del estado ecológico y químico de las aguas subterráneas y superficiales, y para las áreas protegidas. En diciembre de 2008 tendrían que haberse redactados los borradores de los planes hidrológicos de cuenca (Art. 13), para su tramitación y aprobación en diciembre de 2009. Los nuevos planes han de incorporar unos programas de medidas destinados a conseguir el buen estado ecológico de las masas de agua superficiales, subterráneas y zonas protegidas, incluyendo las aguas de transición y costeras, con unos objetivos ambientales que deberían alcanzarse en 2015. Sin embargo, la tramitación de los nuevos planes de cuenca que se rige por el Reglamento de Planificación Hidrológica (RD 907/2007, de 6 de julio) está muy lejos de cumplir el calendario previsto, al menos en los que tienen más incidencia para las regiones de Murcia y Valencia. Este es el caso de los planes del Tajo, Segura y Júcar, que a mediados de 2010 se encontraban encallados en la fase de «Esquema Provisional de Temas Importantes» que precede al «Proyecto de Plan Hidrológico», en gran medida por las fuertes presiones que ha ejercido el gobierno regional de Castilla-La Mancha sobre el Ministerio de Medio Ambiente para anular el trasvase Tajo-Segura y para aumentar el control sobre los recursos del Júcar. Otro factor de complejidad adicional es la sentencia del Tribunal Supremo de 20 de octubre de 2004, que determina la exclusión del Plan Hidrológico del Júcar de las aguas intracomunitarias de las regiones de Valencia y Castilla-La Mancha.

Un rasgo característico de la Ley $11 / 2005$, ha sido su sesgo antitrasvasista y la presencia de flagrantes contradicciones con los principios que pretende defender. En esta «nueva política del agua», auspiciada por el Ministerio de Medio Ambiente, se admite la beligerancia de las comunidades autónomas en detrimento de las competencias del Estado en materia de aguas. Además, se incrementa el riesgo de enfrentamiento entre territorios, en lugar de auspiciar fórmulas de solidaridad, participación y cooperación territorial entre regiones para compartir soluciones y problemas sobre la gestión y calidad del agua. La paralización de las obras de la transferencia del Ebro, iniciadas en febrero de 2004, y su abolición en la citada Ley 11/2005, han alimentado la beligerancia antitrasvasista de los representantes políticos de Castilla-La Mancha, lo que significa un cambio drástico en la postura de dicha región hacia las transferencias de agua. Merece la pena recordar que tanto Castilla-La Mancha como Extremadura emitieron voto favorable al informe final sobre el Plan Hidrológico Nacional, incluyendo el trasvase del Ebro, que fue sometido a votación en el pleno del Consejo Nacional del Agua, el 30 de enero de 2001. La postura antitrasvasista de Castilla-La Mancha quedó refrendada en la propuesta de reforma de su Estatuto de Autonomía, aprobada por las Cortes Regionales en enero de 2007, al incorporar una disposición transitoria primera que imponía la abolición del trasvase Tajo-Segura en el año 2015, coincidiendo con el horizonte establecido en la Directiva Marco de Agua 2000/60/CE para alcanzar el buen estado ecológico de las masas de agua. El principal argumento que 
sustenta dicha exigencia se ampara precisamente en la disposición adicional primera de la Ley 11/2005, de 22 de junio, de modificación del Plan Hidrológico Nacional, que prevé la revisión de los volúmenes trasvasables del Tajo al Segura. La exigencia de Castilla-La Mancha ha ido mucho más allá, al arrogarse competencias estatales sobre la planificación hidrológica y la administración del agua, tanto en la cuenca del Tajo como en la del Segura. Así, en la citada disposición adicional primera de la propuesta de reforma del Estatuto de Castilla-La Mancha (2007), se afirma que los poderes públicos de dicha comunidad autónoma velarán para que «cualquier recurso generado en la cuenca hidrográfica receptora, tanto por las infraestructuras de generación de agua como por las que supongan un ahorro en la utilización de la misma», se destinarían a sustituir los caudales procedentes del trasvase Tajo-Segura. La patrimonialización fáctica de los recursos y de la propia infraestructura del Tajo-Segura que ha pretendido Castilla-La Mancha va mucho más allá, al solicitar que el nuevo Plan Hidrológico de la cuenca del Tajo establezca «la disminución progresiva de los caudales trasvasables, así como el incremento de las reservas no trasvasables para atender las necesidades de la propia cuenca». La propuesta de reforma también incluía en su Preámbulo el establecimiento de una reserva de $4.000 \mathrm{hm}^{3}$ para atender las necesidades de Castilla-La Mancha, y en el articulado también se establecían otras muchas disposiciones que planteaban graves problemas de constitucionalidad (Art. 21, 98, 100, 101, 102, 103, 104, 148, y la Disposición Transitoria Primera), al invadir o limitar por vía estatutaria competencias del Estado en materia de agua establecidas en el artículo 149.2 de la Constitución. Finalmente, el 21 de abril de 2010, la Comisión Constitucional del Congreso de los Diputados paralizó la tramitación de dicho estatuto ante la falta de acuerdo de las dos grandes fuerzas políticas de ámbito nacional.

Idéntica suerte a la del trasvase del Ebro sufrió la conexión Júcar-Vinalopó con punto de toma en Cortés de Pallás, a pesar de que las obras se encontraban en avanzado estado de realización, con sus tramos I, V, VI y VII prácticamente finalizados y con una inversión ejecutada superior a 110 millones de euros. El principal objetivo es la sustitución de bombeos en los acuíferos sobreexplotados del Vinalopó y la garantía de los abastecimientos de agua potable. Por condiciones de coste, calidad y viabilidad técnica, esta finalidad ambiental quedaba garantizada con la toma de Cortes de Pallás, cuyas obras están ya finalizadas. En julio de 2005, con el proyecto ejecutado en más del $50 \%$, se paralizaron las obras sin acreditarse ningún informe técnico validado por los técnicos del Ministerio de Medio Ambiente ni por la Confederación Hidrográfica del Júcar, y a pesar de contar con todos los informes favorables de la Unión Europea, incluyendo una valoración exhaustiva del Banco Europeo de Inversiones.

En gran medida, el detonante de esta paralización fueron las exigencias de los mismos colectivos políticos que propiciaron la derogación del trasvase del Ebro. Sin embargo, en un intento de acallar el fuerte rechazo social de esa decisión en la provincia de Alicante, el Ministerio de Medio Ambiente ha impuesto a los usuarios una «nueva conducción JúcarVinalopó», completamente diferente a la financiada por la Unión Europea, cuya toma se trasladaría al Azud de la Marquesa (Cullera) en la desembocadura del Júcar y que serviría para trasvasar retornos de riego, vertidos de residuales y sobrantes. La deficiente calidad de estos recursos impide su uso como agua potable y, además, deberá acreditarse que son aptos para el riego de hortalizas y otros cultivos sensibles del Vinalopó, que no pueden entrar en contacto con aguas con coliformes y retornos de riego viciados de fitotóxicos. El Real Decreto 1620/2007, de 7 de diciembre, por el que se establece el régimen jurídico de la reutilización de las aguas residuales, prohíbe el empleo de recursos que contengan más de 100 Unidades Formadoras de Colonias (UFC) por cada $100 \mathrm{ml}$. Sin embargo, según los informes ofrecidos por la Confederación Hidrográfica del Júcar, estos valores de referencia 
se han superado sistemáticamente desde 1990 a 2010 en las estaciones de la red de calidad de las aguas (ICA) existentes en el Bajo Júcar, como es el caso del Huerto de Mulet y Cullera, donde se han alcanzado en ocasiones valores de 8.800.000 UFC/100 ml. El uso de dichos recursos para riego precisaría una depuración avanzada, completada con desalación, lo que encarecería notablemente los costes de explotación. Mucho más arriesgado resulta su empleo en abastecimientos de agua potable, no sólo por comprometer seriamente la garantía sanitaria del suministro sino también por el fuerte rechazo psicológico que generaría en la sociedad alicantina el uso de un recurso previamente contaminado con residuales y retornos de riego. Una solución razonable para el problema ambiental que padece el Vinalopó, y uno de los más importantes de la Comunidad Valenciana, podría consistir en emplazar una segunda toma de trasvase antes de la entrada del Júcar en la Ribera, superado el Azud de Antella, que permitiera acceder a un volumen suficiente de recursos para atender las demandas de agua potable del Vinalopó que no pueden sustituirse con desaladoras. Ello sucede en 29 municipios del sistema de explotación Vinalopó-L'Alacantí, con una población cercana a 300.000 habitantes, que demandan alrededor de $44 \mathrm{hm} 3 /$ año, incluidos los consumos industriales.

La paralización del los trasvases del Ebro (2004) y Júcar-Vinalopó (2005) supuso la imposición de una ortodoxia antitrasvasista en la nueva política del agua que asumió el Ministerio de Medio Ambiente a partir de 2004. Como sustitución a los trasvases se apostó por la desalación de aguas marinas como principal alternativa para incrementar la oferta de recursos en las cuencas deficitarias. Para dar forma a esta solución típicamente hidráulica se elaboró el Programa de Actuaciones para la Gestión y Utilización del Agua (A.G.U.A.), recogido en el Real Decreto Ley 2/2004 y en la Ley 11/2005, de 22 de junio, de modificación del Plan Hidrológico Nacional. Es preciso hacer notar que en la tramitación de esta ley no hubo participación del Consejo Nacional del Agua ni de las administraciones públicas, usuarios, técnicos y expertos universitarios para valorar las alternativas posibles. Asimismo, a pesar de su trascendencia territorial, dicha decisión política se adoptó por decreto, de forma unilateral y sin aportar ningún informe de valoración técnica, económica y ambiental que la justificara. El único documento de apariencia técnica que sustentó la paralización del trasvase del Ebro data de 18 de junio de 2004, con el título de «Memoria ambiental comparativa entre las actuaciones urgentes en las cuencas del Mediterráneo y la alternativa al proyecto de transferencias autorizadas por el artículo 13 de la Ley 10/2001, de 5 de julio, del Plan Hidrológico Nacional», cuya autoría recae en la Secretaria General para el Territorio y la Biodiversidad. Dicha memoria, de tan sólo 29 páginas, rebosa argumentos simplistas, faltos de rigor y sin contrastar con los propios trabajos técnicos del Ministerio de Medio Ambiente que fundamentan el Plan Hidrológico Nacional. Todos sus razonamientos y cálculos pretenden exagerar los beneficios de la desalación frente a los enfatizados impactos negativos de la transferencia del Ebro. Para ambas opciones, y de modo superficial, se valoraron aspectos como la superficie de ocupación de suelo, movimientos de tierras, generación de $\mathrm{CO}_{2}$, balance de consumo energético o afecciones a espacios protegidos, que son cuestiones ya evaluadas con gran rigor en trabajos anteriores de los propios técnicos del Ministerio de Medio Ambiente, como la Evaluación Ambiental Estratégica del Plan Hidrológico Nacional (2002).

Por ejemplo, ante un factor tan decisivo como el gasto energético y la generación de $\mathrm{CO}_{2}$, el documento exageraba manifiestamente el impacto negativo del trasvase del Ebro, al elevar el consumo de electricidad a $3,26 \mathrm{kWh} / \mathrm{m}^{3}$, cuando en realidad el consumo neto medio ponderado no supera los $2 \mathrm{kWh} / \mathrm{m}^{3}$, considerando que la energía total de bombeo es de $2.500 \mathrm{GWh}$ y el aprovechamiento energético por turbinación $500 \mathrm{GWh}$. Por el contrario, el consumo de energía de la desalación se reducía a $4 \mathrm{kWh} / \mathrm{m}^{3}$, incluyendo proceso 
de captación, producción y bombeo, cuando lo cierto es que, en desaladoras de última generación con sistema de ósmosis inversa y recuperadores energéticos, como la planta del Canal de Alicante, el gasto unitario de electricidad puede acercarse a $5 \mathrm{kWh} / \mathrm{m}^{3}$ (Prats, D. y Melgarejo, J. 2006). Además, no sólo se exageraba el gasto energético del trasvase del Ebro, sino que también se ofrecían cálculos carentes de todo rigor, al estimar que el consumo de electricidad es uniforme $\left(3,26 \mathrm{kWh} / \mathrm{m}^{3}\right)$ para todas las áreas de uso receptoras, sin considerar volúmenes entregados, bombeos, ni turbinación por tramos. Resulta evidente que, con estos cálculos erróneos, se obtiene un consumo de energía muy superior al real, particularmente en los puntos de entrega más cercanos a la toma en el Bajo Ebro. En este aspecto, es de notar que las Cuencas Internas de Cataluña (190 hm³/año) y ámbitos norte (Castellón) y centro (Valencia) de la demarcación del Júcar (315 hm³/año), tienen la mayor parte de sus áreas de uso urbanas y agrícolas a menos de $100 \mathrm{~m}$ de altitud. En estas zonas estaba prevista la entrega de $345 \mathrm{hm}^{3} /$ año, y para su transporte el consumo real de electricidad oscilaba entre 0,7 y $1,1 \mathrm{kWh} / \mathrm{m}^{3}$, muy lejos de $10 \mathrm{~s} 3,26 \mathrm{kWh} / \mathrm{m}^{3}$ que se utilizaron para calcular la eficiencia energética del trasvase del Ebro. Ocurre igual con gran parte del volumen destinado a la zona sur de la Cuenca del Júcar (Vinalopó), Segura y Sur, donde la mayoría de áreas de uso se ubican por bajo de $200 \mathrm{~m}$ de altitud. Además, salvado el interfluvio de Fuente la Higuera $(553 \mathrm{~m})$, que separa las comarcas valencianas de la Costera y Alto Vinalopó, las fosas tectónicas en descenso escalonado hacia el Segura y Bajo Vinalopó permiten instalar varios saltos hidroeléctricos para turbinar los caudales trasvasados antes de su entrega en destino. En este caso, el consumo neto de energía no habría superado los $2 \mathrm{kWh} / \mathrm{m}^{3}$, muy lejos por tanto de los $3,26 \mathrm{kWh} / \mathrm{m}^{3}$ que se calcularon en la susodicha «Memoria ambiental». En definitiva, el balance energético y de emisiones de $\mathrm{CO}_{2}$ continuaría siendo muy favorable al trasvase del Ebro, si se lo compara con la desalación.

La ausencia de rigor técnico y la improvisación que acompañó a la paralización del trasvase del Ebro, se evidenció años más tarde con el Real Decreto-Ley 3/2008, de 21 de abril, de medidas excepcionales y urgentes para garantizar el abastecimiento de poblaciones afectadas por la sequía en la provincia de Barcelona. En efecto, en dicha ley se recuperaba en esencia el trasvase del Ebro a Barcelona a partir de dos medidas principales. En primer lugar, se ampliaba el ámbito territorial de la Ley 18/1981 que regula el trasvase del Ebro al Campo de Tarragona posibilitando la conexión del Consorcio de Aguas de Tarragona con el Sistema de Abastecimiento Ter-Llobregat (CAT-ATLL). Y en segundo lugar, se preveía que dicha conexión podría ser utilizada para los contratos de cesión de derechos de agua regulados en el texto refundido de la Ley de Aguas. Se advertía que estas dos vías de aportación de agua al Sistema Ter-Llobregat estarían vigentes mientras durase la situación de sequía, sin superar en ningún caso el límite de 4 metros cúbicos por segundo de caudal máximo lijado por la Ley 18/1981 para el trasvase al Campo de Tarragona. Aunque muy reacio a este trasvase, el Gobierno tuvo que aceptarlo por las dificultades de abastecimiento al área metropolitana de Barcelona y la potencia del socialismo catalán, cabeza del tripartito que regía la Generalitat. El proyecto suscitó una fuerte oposición en las comarcas tarraconenses litorales y Aragón, más aún tras las lluvias del mes de mayo siguiente, al entender que había desaparecido la situación de excepcionalidad invocada para su construcción; por último, el Real Decreto-Ley 3/2008 fue derogado por acuerdo de Consejo de Ministros de 6 de junio de 2008 (Gil, A. y Rico, A. 2008 a).

Estos antecedentes confirman, más si cabe, que la decisión política de abolir el trasvase del Ebro vía decreto no estuvo fundamentada en criterios de racionalidad técnica, económica y ambiental. Tampoco en planteamientos hidrológicos, máxime cuando la desalación se presentó como una solución exclusiva y excluyente de otras, que descartaba toda posibi- 
lidad de recurrir a transferencias de menor cuantía y recorrido. En este contexto, no debe extrañar que el Programa A.G.U.A. naciera con una notoria improvisación técnica, que se ha hecho patente en aspectos tan básicos como la falta de concreción en la ubicación de las desaladoras previstas, sus rasgos de diseño, las áreas de uso beneficiadas, las condiciones de financiación o el coste final del agua producida.

\subsection{Las actuaciones del Programa A.G.U.A. en la Comunidad Valenciana y Región de Murcia: ¿más agua, más rápida y más barata?}

La versión inicial del Programa A.G.U.A. preveía 41 actuaciones en la Comunidad Valenciana, que luego fueron ampliadas a 52 en la tramitación parlamentaria de la Ley 11/2005, si bien, debe advertirse que muchas de estas obras figuraban ya en el anexo de inversiones de la Ley 10/2001, del Plan Hidrológico Nacional, como actuaciones complementarias para atender problemas locales. Las inversiones previstas ascenderían a 1.219 millones de euros, y aportarían a la Comunidad Valenciana un volumen de $400 \mathrm{hm}^{3} /$ año, en la forma siguiente:

a)Actuaciones para el incremento de la disponibilidad de recursos hídricos $\left(190 \mathrm{hm}^{3 /}\right.$ año), que básicamente consisten en la construcción de desaladoras en Marina Alta, Marina Baja, Jávea, Alicante, Vega Baja, La Pedrera o Pilar de la Horadada, y programas de agua subterránea y desalación en Castellón.

b)Actuaciones de mejora en la gestión de recursos hídricos $(210 \mathrm{hm} /$ año $)$, que abarcan desde la reutilización de residuales con sistema terciario en la Ribera del Júcar, Vinalopó, Gandía, Jávea o Plana de Castellón, a la modernización de regadíos tradicionales y a la mejora de grandes conducciones e infraestructuras de suministro de agua potable, como el trasvase Júcar-Turia, Acequia Mayor de Sagunto, canal de la cota 100 del Mijares o la red de abastecimiento del área metropolitana de Valencia. En cambio, la Ley 11/2005 no incluía una obra de gran trascendencia como la modernización de la Acequia Real del Júcar, que sí fue contemplada en el Plan Hidrológico Nacional.

En materia de desalación, el Programa A.G.U.A ha acumulado un notorio retraso en la ejecución de las plantas previstas. Así, las obras de construcción de la segunda planta del Canal de Alicante $\left(24 \mathrm{hm}^{3}\right)$ no finalizaron hasta el verano de 2008 y la ampliación de la primera planta, inaugurada en 2003, de 18 a 24 hm $^{3}$ se retrasó a 2006, completando así una inversión ya prevista en la Ley del Plan Hidrológico Nacional (2001). También se licitó, en mayo de 2006, el concurso de proyecto y obra de la desaladora de Torrevieja, de $80 \mathrm{hm}^{3}$ ampliables a $120 \mathrm{hm}^{3} /$ año, por importe de 281 millones de euros. Sin embargo, el proyecto no ha estado exento de polémica por el impacto de las obras de la planta en el entorno de la Laguna de Torrevieja, al que se suma el provocado por la toma de agua y el vertido de la salmuera en el frente marítimo y puerto de la ciudad. A finales de 2010 todavía no se habían completado los colectores de captación de agua marina y de evacuación de la salmuera. Las obras de suministro eléctrico de la planta, que incluyen una línea de alta tensión entre San Miguel de Salinas y Torrevieja, más una subestación eléctrica de 220 kW, tampoco se finalizarían antes de 2012. Además, el proyecto no cuenta con usuarios agrícolas, ya que los regantes del Tajo-Segura, a quienes iría destinado un volumen de $40 \mathrm{hm}^{3} / a$ ño, no pueden asumir unas tarifas de riego que se elevarían a $0,42 \square / \mathrm{m}^{3}$ a pie de planta. Un retraso similar acumulan las desaladoras previstas en Marina Alta y Marina Baja, que entraron en fase de información pública en enero y mayo de 2006, respectivamente. La correspondiente a la Marina Baja, no se construirá finalmente en esta comarca, ya que las obras no se iniciaron hasta 2009 con previsión de finalizarse en 2011, y con el emplazamiento de la planta (18 $\mathrm{hm}^{3}$ ) en Muchamiel, para el abastecimiento del Campo de Alicante. La planta de la Marina 
Alta, prevista en Denia $\left(16 \mathrm{hm}^{3}\right)$, no se había iniciado en 2010. Retrasos similares también han afectado a las desaladoras promovidas por la sociedad estatal Acuamed en Moncófar $\left(10,3 \mathrm{hm}^{3}\right)$ y Oropesa $\left(21,5 \mathrm{hm}^{3}\right)$, cuya construcción se ha visto comprometida por la paralización de varios desarrollos urbanísticos en el litoral de Castellón.

El balance del Programa A.G.U.A. en la Región de Murcia en la provisión de recursos «ex novo» que pudieran sustituir a la transferencia del Ebro tampoco merece una opinión favorable. Prueba de ello es que la mayoría de las desaladoras propuestas ya habían sido programadas en el Plan Hidrológico Nacional, con el agravante de que la puesta en servicio de varias plantas se ha retrasado sensiblemente sobre los plazos previstos. Así ocurre, por ejemplo, con la desaladora de Valdelentisco, en la rambla del mismo nombre, entre Cartagena y Mazarrón, finalizada en el verano de 2008 tras cuatro años de obras, que cuenta con una capacidad inicial de $27 \mathrm{hm}^{3}$, que se destinarán a riego y al abastecimiento de nuevas zonas residenciales. Reseñable es también el retraso que acumuló la ampliación de la desaladora de la Mancomunidad de los Canales del Taibilla en San Pedro del Pinatar $\left(24 \mathrm{hm}^{3}\right)$, que no pudo completarse hasta octubre de 2006 por las dificultades técnicas en la construcción del túnel de toma de agua marina. En el Plan Hidrológico Nacional y Programa A.G.U.A. se planteó la construcción de sendas desaladoras en el Guadalentín y Murcia, respectivamente, además de una actuación denominada «Medidas urgentes para dotar de recursos al Alto Guadalentín». Definitivamente, estas obras se iniciaron en 2007 y se agruparon en una única desaladora en Águilas, con capacidad de $60 \mathrm{hm}^{3}$, para abastecimiento $\left(12 \mathrm{hm}^{3}\right)$ y riego $\left(48 \mathrm{hm}^{3}\right)$ en zonas de los municipios de Águilas, Lorca, Puerto Lumbreras y Pulpí (Almería), aunque no se prevé su finalización hasta 2011. En el Plan Hidrológico Nacional no estaba prevista, como tal, la construcción de una desaladora para garantizar los regadíos del trasvase Tajo-Segura, que el Programa A.G.U.A. situó en la región de Murcia, si bien conviene advertir que ésta se corresponde con la de Torrevieja $\left(80 \mathrm{hm}^{3}\right)$, para riego $(40$ $\mathrm{hm}^{3}$ ) y abastecimiento $\left(40 \mathrm{hm}^{3}\right)$. Esta planta, en ejecución, sustituiría a otras dos desaladoras que el Plan Hidrológico Nacional ubicaba en «La Pedrera» y Pilar de la Horadada, en el límite de las provincias de Alicante y Murcia. Los recursos aportados por estas plantas no suponen una sustitución significativa del agua que el trasvase del Ebro hubiera aportado a la región de Murcia, unos $380 \mathrm{hm} 3 /$ año adicionales.

Resulta obligado subrayar el extraordinario esfuerzo inversor realizado por la Mancomunidad de los Canales del Tabilla para incorporar la desalación como fuente de suministro estratégica y complementaria del Tajo-Segura, con el fin de reducir los riesgos de sequía que padecen la cuenca del Segura y cabecera del Tajo. Antes de la derogación del trasvase del Ebro y de su sustitución por el Programa A.G.U.A., el Ministerio de Medio Ambiente había previsto el desarrollo de un ambicioso plan de desalación para garantizar el suministro de la Mancomunidad a partir de la construcción de cuatro plantas desaladoras que aportarían unos $80 \mathrm{hm}^{3} /$ año. Fruto de ese plan, se han construido las plantas del Canal de Alicante I (24 hm³/año), en Aguamarga (Alicante), y la de León Martínez Campos, en San Pedro del Pinatar ( $24 \mathrm{hm}^{3} /$ año), cuya ampliación ya había sido programada en el Plan Hidrológico Nacional. Asimismo, con fondos del programa A.G.U.A., se han puesto en marcha las desaladoras de Alicante II ( $24 \mathrm{hm}^{3} /$ año) y San Pedro del Pinatar II ( $\left.24 \mathrm{hm}^{3} / a n ̃ o\right)$, si bien ninguna de estas plantas había sido incluida en los Anexos III de «Nuevas actuaciones de interés general» y IV de «Actuaciones prioritarias y urgentes» del Real Decreto Ley 2/2004, de 18 de junio, y de la Ley 11/2005, de 22 de junio, por la que se modifica la Ley 10/2001, de 5 de julio, del Plan Hidrológico Nacional. Además de estas plantas propias, la Mancomunidad también recibe parte de los recursos que genera la desaladora de Valdelentisco (27 hm³/año). Con ello, esta entidad suma una capacidad de producción cercana a $120 \mathrm{hm}^{3} /$ año, que crecerá con otros $50 \mathrm{hm}^{3} /$ año cuando finalicen las plantas de 
Águilas y Torrevieja que construye Acuamed. La reducción de la demanda de agua urbana en el área atendida por la Mancomunidad, ha propiciado que la capacidad de fabricación de agua desalada (170 $\mathrm{hm}^{3} /$ año) sea muy superior a las necesidades actuales de suministro $\left(80 \mathrm{hm}^{3} /\right.$ año$)$, obligando a reducir la producción de algunas plantas, más aún cuando esta fuente no convencional es mucho más cara y menos eficiente en términos de consumo energético que el trasvase Tajo-Segura o que el propio río Taibilla.

El Ministerio de Medio Ambiente ha intentado vincular la ejecución del Programa A.G.U.A. a la sustitución del trasvase del Ebro, y a la posibilidad de aportar «más agua, más rápida y más barata» a través de la desalación. Se ha pretendido difundir la imagen de que la desalación es una técnica de producción de agua más eficiente que las transferencias entre cuencas, olvidando sus costes ambientales, energéticos y económicos. Así, el Programa A.G.U.A. debería aportar a la Comunidad Valenciana $400 \mathrm{hm}^{3} /$ año, volumen próximo al que hubiese recibido del Ebro (350 hm³/año) con las transferencias a Segura y Júcar. El citado Programa debería proporcionar a la región de Murcia alrededor de 200 $\mathrm{hm}^{3} / \mathrm{año}$, mientras que el trasvase del Ebro hubiera aportado $380 \mathrm{hm}^{3} / \mathrm{año}$, lo que revela un déficit de aportación muy elevado, que no ha sido compensado con desaladoras y otras infraestructuras hidráulicas. Asimismo, debe hacerse notar el perjuicio provocado por la derogación del trasvase del Ebro para los regantes valencianos y murcianos, más aún cuando tras seis años de vigencia el Programa A.G.U.A. no ha aportado todavía ningún volumen de agua «ex novo» para riego. Por otro lado, la desalación tampoco constituye una alternativa económicamente viable a la hora de generar recursos para riego por los elevados costes de producción y transporte, que solo pueden soportar algunos cultivos hortícolas de ciclo manipulado, incluidos los ornamentales. A ello, se une la dificultad que entraña aplicar una política de subvención de precios que no cumpla adecuadamente con el Art. 9 de la Directiva Marco del Agua 2000/60/CE, que obliga a introducir «el principio de la recuperación de los costes de los servicios relacionados con el agua». A fecha de hoy, todavía no se ha formalizado ningún acuerdo con los regantes del trasvase Tajo-Segura para el suministro de agua desalada a partir de la planta en construcción en Torrevieja. Así, de los $130 \mathrm{hm}^{3} /$ año de agua desalada que el Programa A.G.U.A pretendía destinar a riego en la cuenca del Segura, los regantes tan sólo han accedido a utilizar unos $18 \mathrm{hm}^{3}$ procedentes de la planta de Valdelentisco. El fuerte incremento de las tarifas eléctricas, y con ello, de los costes de producción de agua desalada explica que los regantes de Alicante y Murcia no puedan asumir los contratos que les ofrece el Ministerio de Medio Ambiente para usar estos recursos. Este factor también ha reducido la producción de agua con destino agrícola en desaladoras inauguradas en la década de los noventa del pasado siglo, como la gestionada por la Comunidad de Regantes Virgen del Milagro de Mazarrón, que sólo funciona en continuo durante el verano. Para abaratar el elevado coste de la desalación $\left(0,90 \square / \mathrm{m}^{3}\right)$ esta entidad recurre al banco de agua de la Confederación Hidrográfica del Segura, mediante un acuerdo con los arroceros de Calasparra ${ }^{2}$. El menor coste de los recursos convencionales y su mezcla con agua desalada, permite alcanzar un precio medio de $0,45 \square / \mathrm{m}^{3}$.

A pesar de esta realidad, en un documento reciente de la Confederación Hidrográfica del Segura titulado «Esquema provisional de temas importantes» (2008), se establecía una tarifa de $0,42 \square / \mathrm{m}^{3}$ para el agua desalada con destino a riego. En otros casos, el Ministerio de Medio Ambiente ha ofrecido agua desalada para riego a $0,30 \square / \mathrm{m}^{3}$. Sin embargo, estudios rigurosos realizados sobre el coste real del agua producida en plantas desaladoras del Programa A.G.U.A. sitúan el coste anual equivalente total en $0,9104 \square / \mathrm{m}^{3}$, lo que

2 Esta situación fue denunciada en prensa por parte de los regantes en el Diario La Verdad, del día 9-92010. 
arrojaría una subvención de $0,49 \square / \mathrm{m}^{3}$ sobre el precio real de dicho recurso (Melgarejo, J. y otros, 2010). Tampoco se precisa si dicha tarifa incluirá el coste de elevación a las zonas regables, que no siempre se encuentran cerca de la costa. Asimismo, la subvención de tarifas no garantiza en modo alguno que pueda generalizarse el empleo de agua desalada en los regadíos murcianos y valencianos, ya que son muy pocos los cultivos que pueden asumir precios de 0,30 ó $0,42 \square / \mathrm{m}^{3}$. Por otro lado, este precio subvencionado se ha ofertado a los regantes sin considerar la espectacular subida de la factura eléctrica producida durante los últimos años, que ha crecido de $0,042 \square / \mathrm{kWh}$ en 2004 a $0,084 \mathrm{kWh}$ en 2010. Si se considera que la producción de agua desalada de origen marino precisa por término medio de $4,5 \mathrm{kWh} / \mathrm{m}^{3}$, lo cierto es que tan solo la factura eléctrica ya sumaría $0,378 \square / \mathrm{m}^{3}$ y, como ha hecho notar, sumado otros costes de inversión, mantenimiento o conservación el precio real supera los $0,90 \square / \mathrm{m}^{3}$.

Además, la posibilidad de aplicar una política sostenible en el tiempo de subvenciones y de discriminación de tarifas por usos tropieza con otra limitación fundamental, como es la gran diferencia de precio que existe entre el agua desalada y los costes que pagan los usuarios de riego y abastecimiento por los recursos convencionales. Por ejemplo, con repercusión íntegra de costes, los regantes del Tajo-Segura han pagado el agua del trasvase durante los últimos años a $0,099 \square / \mathrm{m}^{3}$, y a partir de 2010 a $0,174 \square / \mathrm{m}^{3}$, mientras que la proporcionada por las desaladoras del Programa A.G.U.A. con un precio reducido del 50 $\%$ no bajaría de $0,42 \square / \mathrm{m}^{3}$. En abastecimiento las diferencias son también ostensibles, ya que el precio del agua del Tajo-Segura servida a la Mancomunidad de los Canales del Taibilla ascendía a $0,125 \square / \mathrm{m}^{3}$ hasta 2009 , y a $0,210 \square / \mathrm{m}^{3}$ a partir de 2010 , mientras que la proporcionada por las desaladoras del Plan Hidrológico Nacional y Programa A.G.U.A. se acerca a $0,70 \square / \mathrm{m}^{3}$ y ello sin repercutir la amortización íntegra de las obras.

En realidad, la repercusión de los costes de la desalación sobre los diferentes usuarios es otra de las cuestiones que no ha sido detallada en el Programa A.G.U.A. ni debatida con los usuarios. En desaladoras de última generación, con recuperadores energéticos como la del Canal de Alicante, se consumen $4,9 \mathrm{kWh} / \mathrm{m}^{3}$ y su coste real supera los $0,90 \square / \mathrm{m}^{3}$. El consumo energético en las desaladoras de reciente construcción depende de variables diversas como el sistema de captación del agua bruta (pozos, túneles o toma directa en el mar) y el transporte a planta, pretratamiento, producción y permeado, recuperación energética y bombeo a destino, aunque por término medio puede situarse en $4,5 \mathrm{kWh} / \mathrm{m}^{3}$. Este factor de coste reviste un enorme interés, máxime cuando la electricidad procede, en gran parte, de combustibles fósiles importados y de otras fuentes de producción sujetas a fuerte demanda. La sustitución completa del trasvase del Ebro por agua desalada en las Comunidades Autónomas de Murcia y Valenciana obligaría a desalar unos $730 \mathrm{hm} 3 / a n ̃ o$, que precisarían en torno a 3.200 millones de $\mathrm{kWh} / \mathrm{año}$. De no aumentar la actual capacidad de producción eléctrica, ello obligaría a incrementar la importación de hidrocarburos fósiles que, en el caso de gas natural y petróleo, están sometidos a fuertes oscilaciones de precio por las incertidumbres que conllevan los conflictos bélicos en las principales zonas de producción, y a ello se une la creciente demanda que generan países de gran crecimiento industrial, con los ejemplos prototípicos de China y la India. La moratoria nuclear que adoptó España en 1983, también impediría incrementar el consumo de energía de dicha procedencia. Si se apostara por los parques eólicos para satisfacer la demanda energética de la desalación, harían falta cientos de aerogeneradores de última generación (1 MW); además, esta opción tropieza con serias dificultades para encontrar emplazamientos favorables, a lo que se suma el fuerte impacto paisajístico y ecológico de este tipo de instalaciones en las montañas ibéricas.

Por otro lado, el incremento de la demanda energética a partir de hidrocarburos fósiles supondría alejarse todavía más del cumplimiento del Protocolo de Kyoto, adoptado en 


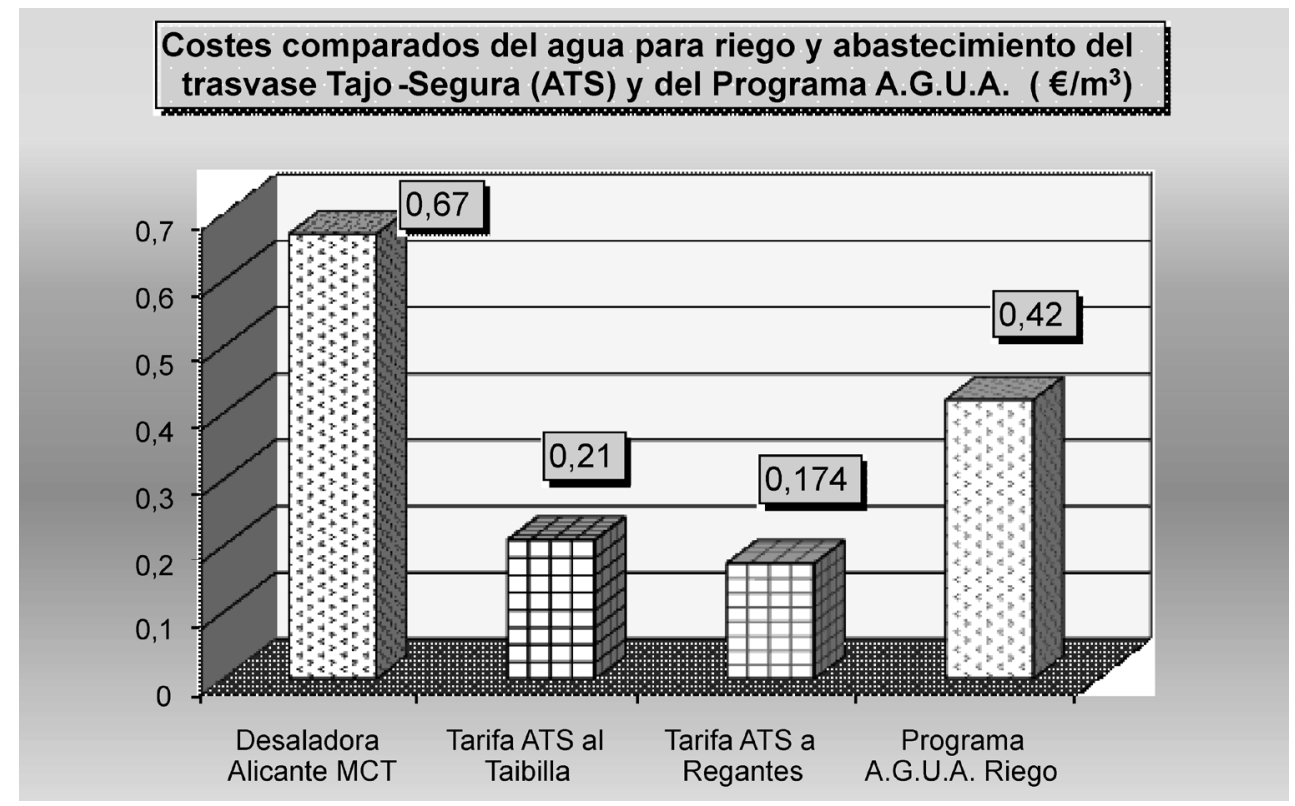

diciembre de 1997. En la Unión Europea se estableció una penalización de 100 euros por tonelada emitida sin permiso a partir de 2008, y, de hecho, por el retraso que acumulan, muchas de las desaladoras previstas en el Programa A.G.U.A. han sido inauguradas después de esa fecha. De esta forma, el coste real del agua desalada podría superar con creces valores de 1 ó $1,25 \square / \mathrm{m}^{3}$. Además, a corto plazo se esperan fuertes incrementos en el precio de la energía eléctrica, más aún cuando la futura regulación del sector que prepara la Unión Europea prevé la liberalización del mercado y la desaparición de las tarifas reducidas reservada a grandes consumidores y a sectores sensibles como el agrícola. De esta forma, la tendencia de reducción de precios en aguas desaladas mantenida durante la última década se ha invertido, debido al incremento de los costes financieros, energéticos y de materiales empleados en la construcción de las plantas. Así, en desaladoras de reciente construcción como las de Hamma (Argelia), Perth y Sydney (Australia) o Moss Landing (California), los costes finales del agua desalada oscilan entre 0,60 y $0,70 \square / \mathrm{m}^{3}$ (Cooley, H., Gleick, P. and Wolf, G., 2006).

Además de los factores de coste, la desalación ofrece otros inconvenientes que conviene ponderar como la gran dependencia tecnológica que se establece hacia países como Japón, en componentes básicos como las membranas empleadas en la ósmosis inversa (Gil, A. y Rico, A. 2008 b). Por otro lado, aunque las aguas desaladas de origen marino ofrecen una baja conductividad, se caracterizan por un acusado desequilibrio químico, con elevada acidez y presencia de ciertos elementos como el boro, que resultan nocivos para abastecimiento y riego. Tampoco se puede desdeñar el impacto de la propia planta al emplazarse en terrenos próximos a la costa, en ocasiones de gran valor ecológico, que también se ven afectados por la necesidad de líneas eléctricas de alta tensión y subestaciones eléctricas de gran potencia (Ródenas, M.A. y Guillamón, J., 2005). En consecuencia, para una futura etapa de planificación hidrológica convendría ponderar los inconvenientes de tipo económico y ambiental que ofrece la desalación, no excluyendo otras alternativas como trasvases mo- 
derados y viables entre cuencas. En los estados más avanzados del mundo en materia de gestión y protección de recursos de agua, se emplean métodos innovadores, basados en el «Análisis del Ciclo de Vida», para valorar con criterios de eficiencia ambiental, económica y energética las diferentes alternativas de suministro de agua. Este método se ha aplicado en Estados Unidos durante los últimos años para evaluar la eficiencia de los trasvases de agua frente a la desalación. Así, en el estado de California la desalación constituye una alternativa considerada mucho menos segura y de mayor impacto ambiental que los trasvases de agua. Los costes de operación de los trasvases «Colorado River Aqueduct» y «State Water Project»son inferiores a $0,19 \square / \mathrm{m}^{3}$, mientras que la desalación arroja costes próximos a $0,60 \square / \mathrm{m}^{3}$; de ahí que esta fuente resulte minoritaria en relación a otras alternativas de suministro como los trasvases. En estos momentos, del agua disponible en el estado de California (45.068 hm³/año), la desalación tan sólo aporta el $1 \%\left(398 \mathrm{hm}^{3} /\right.$ año), mientras los trasvases movilizan $18.872 \mathrm{hm}^{3} /$ año, es decir, el $32 \%$ de los recursos (Stokes and Horvath, 2005).

En España se dispone de unos $111.000 \mathrm{hm}^{3} /$ año, de los cuales estarían garantizados unos $46.000 \mathrm{hm}^{3} /$ año, para satisfacer un consumo efectivo de agua que asciende a 20.784 $\mathrm{hm}^{3} /$ año. Así, en relación a los recursos garantizados, existe un volumen de excedentes que supera los $21.000 \mathrm{hm}^{3} /$ año. En cambio, los trasvases de agua tan sólo movilizan $1.200 \mathrm{hm}^{3} /$ año, es decir, menos del 2,6 \% de los recursos garantizados. La Ley 10/2001, de 5 de julio, del Plan Hidrológico Nacional, proponía unas transferencias mínimas en comparación con las propuestas en el Anteproyecto de 1993 (3.771 hm³ anuales; de los cuales 1.855 procedentes del Ebro), que suponían una solución viable y eficiente, en términos ambientales y económicos para los problemas de agua que padecen las cuencas del Júcar y Segura. Si se hubiera completado la transferencia del Ebro $\left(1.050 \mathrm{hm}^{3} / \mathrm{año}\right)$, el volumen total de agua trasvasada en España habría pasado de 1.200 a $2.250 \mathrm{hm}^{3} /$ año, lo que representaría menos del $5 \%$ de los recursos garantizados y en torno al $2 \%$ de los recursos existentes.

Las cautelas ambientales que se establecieron para el trasvase del Ebro eran las máximas en cumplimiento de la Ley de Aguas de 1985 y de la Directiva Marco de Aguas 2000/60/ CE, y a esa exigencia obedecía la elaboración del Plan Integral de Protección del Delta del Ebro, previsto en la disposición adicional décima de la Ley del Plan Hidrológico Nacional (2001). La existencia de sobrantes suficientes en el Ebro para trasvasar es un hecho admitido generalmente, salvo planteamientos maximalistas. Conviene recordar que, en uno de los primeros informes que elaboró el Ministerio de Medio Ambiente, en mayo de 2004, tras la toma de posesión de la nueva titular, se reconocía explícitamente que era posible la transferencia del Ebro, si bien, con un volumen inferior al previsto en la ley del Plan Hidrológico Nacional (1.050 hm³/año), tras afirmar que «teniendo en cuenta la necesidad de asegurar los caudales ambientales en el Delta del Ebro y la capacidad de regulación de los embalses de Mequinenza y Ribarroja, la realidad es que los usuarios no podrían recibir más de $620 \mathrm{hm}^{3} / a \tilde{n} o$ en condiciones suficientemente garantizadas» (MMA, 2004). Así pues, con criterios técnicos, se admitía la viabilidad ambiental de una transferencia con origen en el Bajo Ebro, que podría superar los 600 hm³/año, es decir, más que la capacidad del trasvase Tajo-Segura. Dicho volumen, podría servir para atender los déficits de agua de Barcelona, Comunidad Valenciana y Región de Murcia, mediante una estrategia de diversificación de riesgos frente a las sequías, combinando transferencias, recursos subterráneos renovables, desalación y reutilización de residuales.

Transcurridos ya cuatro años desde la abolición del trasvase del Ebro, el Programa de Actuaciones para la Gestión y Utilización del Agua (A.G.U.A.), que impuso el Gobierno por la vía del Real Decreto Ley 2/2004 y en la Ley 11/2005, de 22 de junio, de modificación del Plan Hidrológico Nacional, no ha aportado soluciones definitivas ni sostenibles 
a los problemas de escasez de agua que sufren las Comunidades Autónomas de Murcia y Valenciana. Las urbanas son las únicas demandas que han experimentado ciertos avances en garantía y calidad de suministro con las desaladoras construidas en la costa, si bien persisten los problemas de abastecimiento que padecen áreas de uso situadas en el interior de Murcia (Altiplano de Jumilla-Yecla) y Alicante (Vinalopó). En cambio, con el Programa A.G.U.A. dista mucho de haber mejorado la situación de garantía de las demandas agrícolas, que continúan padeciendo una fuerte infradotación. Tampoco se ha atendido el grave problema ambiental que supone la sobreexplotación de acuíferos y la falta de recursos para garantizar caudales ambientales en ríos y humedales. La percepción generalizada entre los regantes, sobre todo entre los murcianos y alicantinos, es que el regadío ha sido el gran perjudicado por la abolición del trasvase del Ebro y por la actuaciones previstas en materia de desalación dentro del programa A.G.U.A. A ello se une la enorme preocupación existente entre los regantes sobre el incierto futuro que aguarda al trasvase Tajo-Segura, vital para las provincias de Murcia y Alicante, cuya supervivencia se ha visto amenazada por la actitud beligerante de Castilla-La Mancha, que pretende el pleno control sobre los recursos del Tajo, como así recogía la propuesta de reforma de su estatuto de autonomía que finalmente fue retirada de la Comisión Constitucional del Congreso de los Diputados en abril de 2010.

\section{Bibliografía}

AGUAS DEL JÚCAR, S.A. (2005): Análisis del cambio de toma del Júcar-Vinalopó de Cortes al azud de la Marquesa, abril de 2005 (policopiado).

ARROJO AGUDO, P. (2001): «Análisis Económico del PHN: de la inconsistencia a la prevaricación técnica», en El Plan Hidrológico Nacional a Debate, Ed. Bakeaz, Bilbao, pp. 11-29.

CABEZAS CALVO-RUBIO, F. (2005): Trasvase Júcar-Vinalopó. Análisis de alternativas, diciembre de 2005 (policopiado).

CABEZAS CALVO-RUBIO, F., CABRERA MARCEL, E. Y MORELL EVANGELISTA, I. (2008): El agua: una cuestión de Estado. Perspectiva desde la Comunidad Valenciana. Asociación Valenciana de Empresarios (AVE), (documento policopiado), $121 \mathrm{p}$.

CALVO GARCÍA-TORNEL, F. (2002): «Plan Hidrológico Nacional y déficit estructural en la Cuenca del Segura», Insuficiencias Hídricas y Plan Hidrológico Nacional, Instituto Universitario de Geografía, Universidad de Alicante. Alicante, pp. 319-346.

CONFEDERACIÓN HIDROGRÁFICA DEL JÚCAR (1999): Plan Hidrológico de la Cuenca del Júcar, Ministerio de Medio Ambiente, Valencia, 32 pp.

CONFEDERACIÓN HIDROGRÁFICA DEL SEGURA (1992): Plan Hidrológico. Proyecto de Directrices, 241 págs. (policopiado).

CONFEDERACIÓN HIDROGRÁFICA DEL SEGURA (2008): Esquema provisional de temas importantes. Demarcación Hidrográfica del Segura. Ministerio de Medio Ambiente y Medio Rural y Marino. Documento policopiado, $172 \mathrm{p}$.

COOLEY, H., GLEICK, P. AND WOLFF, G. (2006): Desalination, with a grain of salt: a California perspective. Pacific Institute for Studies in Development, Environment and Security, California, $88 \mathrm{p}$.

EZCURRA CARTAGENA, J. (2002): «El trasvase Tajo-Segura». En La Confederación Hidrográfica del Segura (1926-2001), Ministerio de Medio Ambiente, Murcia, pp. 261-278.

GIL OLCINA, A. (2002): «De los Planes Hidráulicos a la Planificación Hidrológica», Insuficiencias hídricas y Plan Hidrológico Nacional, Instituto Universitario de Geografía. Universidad de Alicante, Caja de Ahorros del Mediterráneo, pp. 11-44.

GIL OLCINA, A. y MORALES GIL, A. (eds.) (1995): Planificación Hidráulica en España, Fundación Caja del Mediterráneo, Alicante, 430 pp.

GIL OLCINA, A. y MORALES GIL, A. (eds.) (1999): Los usos del agua en España, Instituto Universitario de Geografía, Universidad de Alicante y Caja de Ahorros del Mediterráneo, Alicante, $681 \mathrm{pp}$. 
GIL OLCINA, A. y RICO AMORÓS, A.M. (2007): El problema del agua en la Comunidad Valenciana, Fundación Agua y Progreso de la Comunidad Valenciana, 240 pp.

GIL OLCINA, A. y RICO AMORÓS, A.M. (2008 a): Políticas del Agua II. Mejora y Ampliación de los Riegos de Levante. ESAMUR y EPSAR, Murcia, 516 p.

GIL OlCINA, A. y RICO AMORÓS, A.M. (2008 b): Políticas del Agua II. De la Ley de Aguas de 1985 al PHN. ESAMUR y EPSAR, Murcia, $484 \mathrm{p}$.

GÓMEZ ESPÍN, J. Ma , GIL MESEGUER, E. y GARCÍA MARÍN, R. (2006): El antes y después de la modernización de regadios. La experiencia de Mula. Servicio de Publicaciones de la Universidad de Murcia, Murcia, $142 \mathrm{p}$.

HERNÁNDEZ HERNÁNDEZ, M., RICO AMORÓS, A.M. y JUÁREZ SÁNCHEZ-RUBIO, C. (2010): «Conflicts over water and land use on the coastline of the región of Valencia: agricultura versus the urban city», in The suistainable city. Urban regeneration and suistainability, Editorial WIT Press, pp. 405-417.

MEDINA GIL A. (2004): «Infraestructuras del trasvase del Ebro en Alicante», en Repercusiones socioeconómicas del Plan Hidrológico Nacional en la provincia de Alicante, COEPA e Instituto del Agua, Universidad de Alicante, pp. 323-349.

MELGAREJO, P. Y MELGAREJO, J. (2006): Informe sobre la conducción Júcar-Vinalopó y la nueva alternativa planteada para la toma en la desembocadura, enero de 2006.

MELGAREJO MORENO, J., MOLINA JIMÉNEZ, A. Y DEL VILLAR GARCÍA, A. (2010): El valor socioeconómico del trasvase Tajo-Segura: análisis jurídico y económico ante la hipótesis de su reducción o cancelación, COEPA y Fundación Agua y Progreso de la Generalidad Valenciana, Alicante, $175 \mathrm{p}$.

MINISTERIO DE MEDIO AMBIENTE (1998): Libro Blanco del Agua en España, Secretaría de Estado y Aguas del Ministerio de Medio Ambiente, Madrid, 855 ppsp.

MINISTERIO DE MEDIO AMBIENTE (2000): Plan Hidrológico Nacional: Análisis ambientales. (Documento policopiado), Madrid, 266 págs.

MINISTERIO DE MEDIO AMBIENTE (2000): Plan Hidrológico Nacional: Análisis de antecedentes y transferencias planteadas. (Documento policopiado), Madrid, $222 \mathrm{pp}$.

MINISTERIO DE MEDIO AMBIENTE (2000): Plan Hidrológico Nacional: Análisis de los Sistemas Hidráulicos, (Documento policopiado) Madrid, $390 \mathrm{pp}$.

MINISTERIO DE MEDIO AMBIENTE (2000): Plan Hidrológico Nacional: Análisis económicos. (Documento policopiado), Madrid, 390 págs.

MINISTERIO DE MEDIO AMBIENTE (2000): Plan Hidrológico Nacional: Delimitación y asignación de recursos hidráulicos compartidos» (Documento policopiado), Madrid, 130 págs.

MINISTERIO DE MEDIO AMBIENTE (2002): Evaluación Ambiental Estratégica del Plan Hidrológico Nacional. Documento de Síntesis. (Documento policopiado), Madrid, 186 pp.

MINISTERIO DE MEDIO AMBIENTE (2004): Memoria ambiental comparativa entre las actuaciones urgentes en las cuencas del Mediterráneo y la alternativa al proyecto de transferencias autorizadas por el artículo 13 de la Ley 10/2001, de 5 de julio, del Plan Hidrológico Nacional. Secretaría General para el Territorio y la Biodiversidad, (Documento policopiado), Madrid, 29 p.

MIRÓN LÓPEZ, M. (2002): «El déficit hídrico estructural de la cuenca del Segura». En La Confederación Hidrográfica del Segura (1926-2001), Ministerio de Medio Ambiente, Murcia, pp. 311-322.

MORALES GIL, A. (2001): Agua y Territorio en la Región de Murcia, Fundación Centro de Estudios Históricos e Investigaciones Locales Región de Murcia, Murcia, 270 pp.

MOREU BALLONGA, J.L. (2006): «Propiedad, usos, transmisión y precio de las aguas públicas y de las aguas privadas». En Campos, P., Casado, J.M. y Maestu, J. (eds) Hacia las cuentas económicas del agua en España, Consejo General de Colegios de Economistas, Madrid, pp. 29-90.

OLCINA CANTOS, J. (2002): «Planificación hidrológica y recursos de agua no convencionales en España», en Insuficiencia Hídrica y Plan Hidrológico Nacional, Instituto Universitario de Geografía, Universidad de Alicante, Caja de Ahorros del Mediterráneo, pp. 69-130.

PRATS RICO, D. Y MELGAREJO MORENO, J. (2006): Desalación y reutilización de aguas. Situación en la provincia de Alicante. Fundación Coepa, Alicante, 164 págs.

RICO AMORÓS, A.M (2006): «Políticas agrarias, eficiencia socioeconómica y retos de futuro en los regadíos intensivos», Boletín de la Asociación de Geógrafos Españoles, nº 41, págs. 113-149. 
RÓDENAS CAÑADA, M.A. Y GUILLAMÓN ÁLVAREZ, J. (2005): «Trasvases y desalación. Tiza y pizarra». En Ingeniería y Territorio, $\mathrm{n}^{\circ} 72$, Revista del Colegio de Ingenieros de Caminos, Canales y Puertos, Barcelona, pp. 26-37.

RODRÍGUEZ ESTRELLA, T., GARCÍA MARIANA, F. y MONTANER SALAS, E. (2004): «De freáticos someros a acuíferos profundos en la Cuenca del Segura», en La Cultura del Agua en la Cuenca del Segura, Fundación Cajamurcia, Murcia, pp. 479-513.

STOKES AND HORVATH (2005): «Life-cycle Energy Assesment of Alternative Suply Systems». International Journal of LCA, sumitted.

VERA REBOLLO, J.F. Y RICO AMORÓS, A.M. (1995): «Los sistemas de abastecimiento de agua potable en un espacio turístico y residencial: la Costa Blanca». En Agua y Espacios de Ocio, Universidad Internacional Menéndez Pelayo, Fundación CAM, Alicante, pp. 105-150. 
